\title{
Bridging the Gap Between Mammal and Insect Ears - A Comparative and Evolutionary View of Sound-Reception
}

\author{
Ben Warren ${ }^{1}$ and Manuela Nowotny ${ }^{2 *}$ \\ ${ }^{1}$ Department of Neuroscience, Psychology and Behaviour, University of Leicester, Leicester, United Kingdom, ${ }^{2}$ Animal \\ Physiology Group, Institute of Zoology and Evolutionary Research, Friedrich Schiller University, Jena, Germany
}

\section{OPEN ACCESS}

Edited by:

Fernando Montealegre- $Z$, University of Lincoln, United Kingdom

Reviewed by:

Daniel Robert,

University of Bristol, United Kingdom Matthew Su,

Nagoya University, Japan

*Correspondence:

Manuela Nowotny

manuela.nowotny@uni-jena.de

Specialty section:

This article was submitted to Behavioral and Evolutionary Ecology,

a section of the journal

Frontiers in Ecology and Evolution

Received: 12 February 2021

Accepted: 12 July 2021

Published: 29 July 2021

Citation:

Warren B and Nowotny M (2021)

Bridging the Gap Between

Mammal and Insect Ears -

A Comparative and Evolutionary View

of Sound-Reception.

Front. Ecol. Evol. 9:667218.

doi: $10.3389 /$ fevo.2021.667218
Insects must wonder why mammals have ears only in their head and why they evolved only one common principle of ear design-the cochlea. Ears independently evolved at least 19 times in different insect groups and therefore can be found in completely different body parts. The morphologies and functional characteristics of insect ears are as wildly diverse as the ecological niches they exploit. In both, insects and mammals, hearing organs are constrained by the same biophysical principles and their respective molecular processes for mechanotransduction are thought to share a common evolutionary origin. Due to this, comparative knowledge of hearing across animal phyla provides crucial insight into fundamental processes of auditory transduction, especially at the biomechanical and molecular level. This review will start by comparing hearing between insects and mammals in an evolutionary context. It will then discuss current findings about sound reception will help to bridge the gap between both research fields.

\section{Keywords: auditory evolution, insect hearing, mammal hearing, auditory transduction, hearing biomechanics}

\section{INTRODUCTION}

Detection of air-borne sounds can enable animals to perceive key information about conspecifics, predators and prey over long distances and with a high directional precision. Both, insects and mammals have evolved unique and fascinating solutions-often with common principles of operation - to identical problems of sensitive sound detection, frequency discrimination and sound localization. In this review we compare and contrast evolution and present day function of ears in insects and mammals. We discuss this in the context of evolutionary drivers and constraints that sculpted them through $\sim 600$ million years of evolution since they separated. We start with Early aquatic evolution of primary mechanosensitive receptors which accounts for nearly a third of the evolutionary time since the last common ancestor of insects and mammals. Once animals ventured onto land $\sim 400$ million years ago (MYA) it is informative to list and appreciate the Evolutionary drivers and constraints of mammal and insect ears that act on the auditory organs, including predator detection, conspecific communication and prey detection. We address the evolutionary innovations of ear physiology, through the constrains of both their evolutionary history, i.e., natural selection can only work on the range of phenotypes a species has, and the physical properties of sound propagation and detection by biological systems. We then review the function of today's insect and mammalian ears in the sections Convergent evolution: sculpting similar biomechanical function of ears and Convergent evolution: mechanisms of sound amplification. 
It is a testament to the strict laws of physics and the persistent, harsh and relentless selection pressures of hearing that the same optimal solutions are found both in insects and mammals. Finally, we delve into the Mode of transduction-closing the gap on the identity of the transduction ion channel in mammals and insects. Insect and mammalian ears are exquisitely tuned for their respective detection of sound. Although they use homologous development genes to control ear development and uncannily similar molecular mechanisms, this is achieved through a combination of similar and different protein components. Identifying and confirming the identity of the transduction channel-different between insects and mammals-has proved especially challenging in both animals and as each research field closes in on the transducer identity it is an especially exciting time to review the progress.

\section{EARLY AQUATIC EVOLUTION OF PRIMARY MECHANOSENSITIVE RECEPTORS}

The earliest life existed some $\sim 3.7$ billion years ago in a hot, oxygen-poor primordial broth (Garcia et al., 2017) of simple single-celled prokaryotic organisms. A tapestry of membrane-bound receptor proteins enabled interactions with their environment. Some two billion years later eukaryotes evolved out of an endosymbiotic amalgamation of prokaryotic components (Cooper, 2000; Knoll, 2004). One key difference that evolved in eukaryotes, was a microtubule cytoskeleton. This linear repeating chain of tubulin proteins would later push finger-like protrusions out into the environment: flagella/cilia (Mitchell, 2004; Jékely and Arendt, 2006; Satir et al., 2008). Their ensuing rhythmic bending created water currents necessary to filter and ingest food but also endowed cell motility so that, together with the adaptability of this new eukaryotic form, single celled life could move to exploit new environmental niches. The basic cytoskeleton of cilia-their nine doublet microtubules that form an elongated internal ring (Figure 1)-are ubiquitous in all branches of eukaryotes and evolved before the last eukaryotic common ancestor (Doolittle et al., 1996; Douzery et al., 2004; Berney and Pawlowski, 2006; Mitchell, 2007). This microtubule flagellum is hypothesized to have been such a competitive advantage that it was the only eukaryote whose descendants survive to this day (Mitchell, 2007). In addition, cilia acted as sensory antennae where receptor proteins congregate. This innovation proved key to the formation of all specialized sensory organs of today's eukaryotes-insect and mammalian (Moran et al., 2014).

From single-celled organisms sprouted multicellular life, nearly two billion years after first single-celled life (Knoll, 2004). Using minimum evolution criterion of the molecular clock, which aligns with the geological record, recent analyses put the last common ancestor of vertebrates and invertebrates as late as 573 MYA (Peterson et al., 2004) and as early as 634 MYA (Peterson and Butterfield, 2005). This is well before the Cambrian explosion of complex life and ecosystems (541 MYA) and well before animals appear in the fossil record (Knoll, 2004). It is speculated that the last common ancestor of invertebrates and vertebrates - termed Urbilaterian (Figure 1) - had a well-defined body-axis (de Robertis and Sasai, 1996) bearing a head with dedicated sensory systems including photoreceptors (Arendt and Wittbrodt, 2001) with probably nine opsins (Ramirez et al., 2016), a gut (Hejnol and Martindale, 2008) and touch-sensitive appendages, equipped with sensory cilia linked to a nervous system (Carroll et al., 2001). The common origin of the sensory systems of invertebrates and vertebrates in this Urbilateria is strikingly evidenced by a suite of homologous genes in today's insect and mammals. For example, both modern-day flies and mammals have different but homologous pro-developmental genes for ear development (Math1 and Atonal, Figure 1) and eye development (Pax6) that can be functionally swapped between them (Xu et al., 1999; Wang et al., 2002; Weinberger et al., 2017). Such genetic conservation is not limited to sensory systems and it appears that the basic genetic architecture for a bilateral body design already existed before invertebrate and vertebrates became two distinct animal groups. In this respect, we could think of the widespread genetic homology in animals not in terms of the relatively short evolutionary time that they shared in this animal form, but the evolution of a genetic and developmental program that was ready at an optimal moment; at the start of the Cambrian explosion and flourished during it when all of today's animal lineages were established-an enduring unchallenged bilateral monopoly on nearly all animal life on earth (Knoll, 2004).

The vertebrate multiciliate receptor cells, called hair cells, are thought to have evolved even before a centralized dedicated mechanoreceptive system in aquatic vertebrates [similar to modern day ascidians or filter feeders (Burighel et al., 2003)]. The integration of hair cells into a dedicated head-based mechanosensory organ was the first of two major milestones in the evolution of vertebrate hearing that took place in a purely aquatic environment. Evolution would sculpt this prototypical mechanoreceptive organ to fulfill the selective pressures of vertebrates to hear as they diversified into terrestrial niches. The earliest fossil evidence of an internalized mechanoreceptor is from an early (pre-Devonian age $>416$ MYA) vertebrate armored "fish" creature-the Ostracoderm Protopteraspis micra (Figure 1; Stensiö, 1927). Embedded in the skull are bilateral labyrinths, resembling basic acceleration or balance organs. Ostracoderms, with their bilateral balance organs, were so prosperous that they gave rise to most vertebrates alive today over their 100-millionyear reign (Forey and Janvier, 1994; Janvier, 2008). The second milestone, evolution of an articulating jaw, is first evidenced in another type of armored fish, placoderms, with the earliest fossil 419 Million years old (Zhu et al., 2013). Evolution of the jaw was a key innovation that allowed jawed vertebrates (Gnathostomes) to outcompete their jawless competition, probably first for buccal (mouth)-based respiration (Mallatt, 1996), then for biting and chewing their prey; few jawless chordates, such as the lamprey, exist today. The evolution of an articulating jaw transmitting sound-induced bone vibration to the ear was essential for the evolution of hearing of all vertebrates over the next 300 million years of terrestrial evolution.

Invertebrate evolution, like vertebrates, was constrained to an aquatic environment. The first terrestrial fossil tracks come 


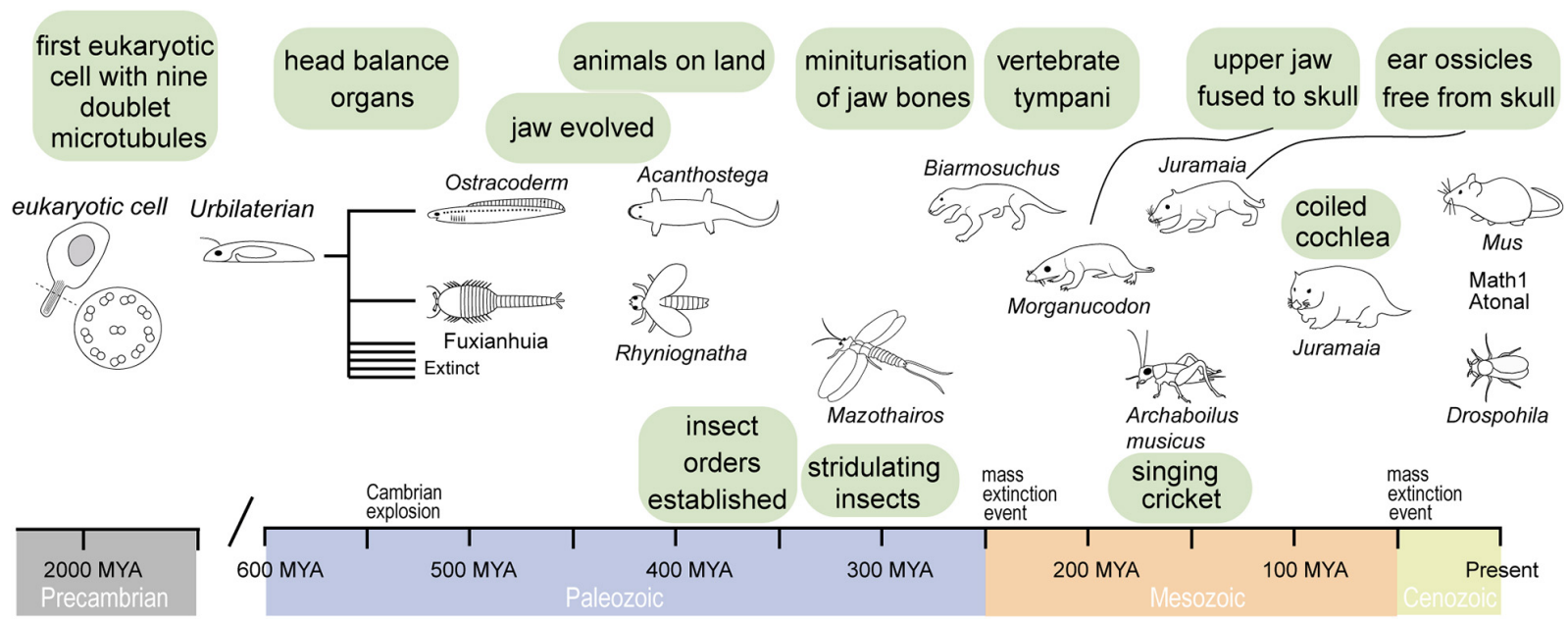

FIGURE 1 | Timeline of evolution of important ear structures in vertebrates and invertebrates that have a common ancestor in the Urbilaterian. This bilateral organism probably had already mechano-sensitive cells.

from invertebrates, dated around 480 MYA (MacNaughton et al., 2002). Phylogenetic analysis puts the appearance of insects around the same time (Misof et al., 2014). Such tracks are thought to represent transient incursions on land of marinebased invertebrates but provide also evidence for the ease at which invertebrates can exploit terrestrial niches. Their hard exoskeleton could support their body weight and prevent desiccation out of water-unique advantages over their vertebrate counterparts. In contrast to vertebrates, aquatic invertebrates did not evolve a central mechanosensitive organ, from which all insect ears evolved. What proved crucial for insect ear evolution was their widespread proprioceptors present in all their articulating joints necessary for sensing all their movements. These proprioceptors formed the basis of all insect sound detecting organs.

\section{EVOLUTIONARY DRIVERS AND CONSTRAINTS OF MAMMAL AND INSECT EARS}

\section{Mammals}

From water to land, the first vertebrate ears are speculated to have taken their first evolutionary steps in semi-aquatic tetrapods that straddled the aquatic-terrestrial shoreline. One of the earliest terrestrial tetrapods, such as Parmastega aelidae and Acanthostega (Figure 1) gives us a glimpse of these aquaticterrestrial transitional forms of vertebrates. P. aelidae obtained oxygen from both water-as assumed from nostrils positioned under the water line-as well as from the air-through a spiracle opening at the back of the head above the water line (Beznosov et al., 2019). As these early tetrapods evolved, the nostrils became larger and migrated above the water line to permit oxygen to be obtained solely from the air. This fossil record not only evidences their advancement onto land but sets the stage for airborne detection of sound that requires head-based air conducting channels to funnel sound to the balance organs of their aquatic ancestors-that would (much) later evolve into organs dedicated to detect airborne sound-ears. At this time $\sim 400$ MYA, however, the bilateral balance organs of gnathostomes had already evolved over $\sim 150$ million years in aquatic environments to detect lowfrequency head-based accelerations necessary for the control of swimming (van Bergeijk, 1967; Baird, 1974). Such lowfrequency detecting organs were quite unsuited for detecting higher frequency airborne sound. The frequency range of their balance organs was only one of two more substantial barriers to the detection of airborne sound. The first was a lack of structures [such as tympani (ear drums)] to capture sound energy, in the form of sound pressure differences. The second was a lack of structures (a middle ear) to transmit any airborne sound energy to their internal balance organs-so called impedance transformers because air-borne sound must be converted into vibrations of the high impendence saline that bathes the sensory receptors. Our interpretation goes against the "standard view" (Lombard and Bolt, 1979) that aerial hearing evolved soon after tetrapods moved onto land. In defense of our interpretation, there was a complete lack of middle ear specializations for hearing in early tetrapod animals that represent the five major amniote lineages (Clack and Allin, 2000) and no tympani were even thought to exist for early aquatic tetrapoda (Allin and Hopson, 1992; Clack and Allin, 2000). Their balance organs were perfectly sufficient to detect the footfall of predators or competing conspecifics through surface-borne ground vibrations, picked up by conduction of sound through the leg and then jaw. It is hence debatable if these first tetrapoda "heard" anything that we would call sound, induced by pressure changes in air. Modern amphibians lack middle ear cavities, but still sensitivity detect the vibration of predators. Therefore, vibration detection through limbs, which are in contact with the ground proves an effective strategy and, hence, why vertebrates were in no hurry to evolve solely aerial hearing (Hildebrand and Goslow, 1995). In 
support of this, there is a secondary loss of specialized air-borne receivers in favor of surface-borne vibrations in amphibians like salamanders (Wever, 1978; Hetherington, 1992). As such, the first evolutionary steps to the solely aerial hearing system of today's mammals were probably in the form of better coupling of ground-borne vibrations to their balance organs.

Middle ear evolution began with a bone later to become the stapes, which in present day mammals feeds sound vibrations into the cochlea. About 400 MYA ago the stapes had an obvious structural role to stabilize articulation of the jaw for breathing and chewing, but crucially it bridged between the otic (ear) bone and the upper jaw (Clack, 1992). Early fossils of aquatic tetrapoda, Acanthostega and Ichthyostega (Clack, 1992; Clack et al., 2003), suggest that, in addition to its main structural role, the stapes already served to transmit ground-borne vibrations to the inner ear in early semi-aquatic tetrapods (Clack, 1983). From an extensive fossil record of vertebrates, we know that two former lower jaw bones underwent a change of function and became also part of the mammalian middle ear (Reichert, 1837). It is hypothesized that miniaturization of the jaw was the primary driver for the transformation of the jaw joint (Lautenschlager et al., 2018) and that the transformation of the jaw elements into cranial ear bones occurred several times in the mammal evolution. Allotheria, an extinct group of early mammals, evolved a unique palinal joint as a feeding adaption, whereas other Mammaliaformes have hinge joints (Han et al., 2017). However, the incus and malleus decoupled in different stages from the lower jaw and only function in sound transmission in modern mammals (Lopatin, 2019). Due to the poor preservation, the origin of the tympanum in the different vertebrate taxa is less understood. It is believed that tympana also evolved independently several times in vertebrates (Grothe and Pecka, 2014) and is based on thinning of the skin of the lateral head. Two main hypotheses are discussed for the origin of the tympanum holding bone elements; one origin is considered by a postquadrate tympanum and another by a postdentary tympanum (Gaetano and Abdala, 2015).

Based on the fossil record of small rodent-like mammals like Sinoconodon and Morganucodon (Figure 1), the cochlea 200 MYA was little more than a thumb-like stump (Graybeal et al., 1989; Luo and Ketten, 1991) less than $2 \mathrm{~mm}$ long (Zhexi et al., 1995). By the end of the Jurassic period, the cochlea of Dryolestoida, a basal relative to marsupial and placental mammals, had coiled by about three quarters. As the length of cochlea correlates with the frequency range of hearing, this fossil record suggests an evolutionary trajectory in mammals toward ever higher frequency hearing (West, 1985). The selection pressures that drove our Mesozoic mammalian ancestors to specialize sensitive, high frequency hearing are threefold (Meng and Wyss, 1995). During the Jurassic mammals exploited nocturnal niches in the face of larger predatory dinosaurs (Liu et al., 2018). Due to this there was large selection pressure for sensitive hearing as visual information was more limited at night. Secondly, an effective sound shadow to allow small mammals to detect the direction of sound-through comparative differences in sound amplitude at their ears-is only effective for high frequencies (Schnupp and Carr, 2009). Finally, vocalizing at higher frequencies would have made their larger low-frequency hearing predators less likely to hear and locate them, giving them a further selective advantage.

\section{Insects}

About 40 Million years after the colonialization of land by plants (Early Silurian, about $480 \mathrm{Ma}$ ), and probably before vertebrates established themselves on land, ectognathous insects such as Rhyniognatha (Figure 1, including Orthoptera, what we would recognize today as crickets, bush crickets and locusts) were present. Their descendants went onto evolve acoustic communication but the earliest proof of insects producing sound is from a Permian insect, Permostridulus brongniarti that existed 260 MYA (Béthoux et al., 2003). This is based on its specialized grooved veins under the wing-modern day crickets rub this vein along its other wing to stridulate and produce mating calls. The ability to produce sound does not necessarily imply the ability to hear. However, tympanal membranes on forelegs are found in Triassic and Jurassic fossils (Zeuner, 1939; Plotnick and Smith, 2012) and most modern-day Orthoptera that stridulate have ears (Jost and Shaw, 2006). Later stridulating insects such as Archaboilus musica 165 MYA (Gu et al., 2012), in the Jurassic, and Tertiary Pseudotettigonia amoena 55 MYA (Rust et al., 1999) shows that Orthoptera maintained the ability to produce sound through stridulation. It is likely that ears evolved to hear this stridulating sound, due to its high reproductive advantage for conspecific localization. During the Jurassic, as Archaboilus musica was chirping, other acoustic groups such as Diptera and Lepidoptera diverged alongside the radiation of flowering plants (Doyle, 2012).

There is further reason to believe that insect ears evolved early in their terrestrial occupation and this is the apparent evolutionary ease of acquiring a sound sensitive organ for insects. Whereas all vertebrate ears evolved from specialized head-based acceleration organs, insects' ears, by contrast, evolved from proprioceptors littered throughout their body. While the evolutionary barriers for vertebrates were formidable-evolution of middle ears (for impedance transformation) thinning of bone to form a tympanum (to capture sound pressure)-insects already possessed three components to form ears-in abundance. Their stretch- and vibration-sensitive proprioceptors, which are widely dispersed throughout their body, evolved into the auditory receptor cells, the tympani were a "simple" evolutionary thinning of their exoskeleton and the impedance of airborne sound could be simply matched by the backing the tympanum with their ample tracheal network filled with air. This evolutionary ease is evidenced by the independent evolution of several tympani-found in at least 10 different body parts, across several insect taxa (Fullard and Yack, 1993) and the high diversity of insect tympanal ears.

If we dive deeper into the morphology of insects and compare insects either with or without a tympanum (atympanate) in closely related taxa, here proprioceptors that monitor body motions in atympanate insects, acquire an auditory response with little change in their morphology (Yack and Fullard, 1990, 1993). An intuitive example is the proprioceptors in the "knee" joint of ancient insects that, was anchored at either end, and 
suspended between, the tibia femur joint. As the tibia-femur joint flexed the stretch-sensitive neurons were stretched and activated. These proprioceptors were also ideally placed to detect substrate borne vibration; much like early tetrapods that detected vibration by conduction through their legs (and jaw) to their headbased mechanosensitive organs. In extant crickets this single proprioceptor has evolved into three distinct sensory organs each with their own afferent nerve bundle (see review Strauß and Lakes-Harlan, 2014): the subgenual organ, intermediate organ and the crista acustica. The archetypal composition of the receptor cell complex, known as a chordotonal organ (Kavlie and Albert, 2013), is similar in all of these three organs, only the connection to the structure that picks-up the signal differs: Sensory cells of the subgenual organ are connected to the cuticle of the leg, to detect vibration (Kühne, 1982), the cells of the crista acustica are found on top of an inner air-filled trachea in the leg to detect high frequency sound that travels along the trachea (Hedwig, 2014). Evolution of dedicated sound receivers in many other extant insect groups involved the thinning of the cuticle onto which the receptor cells were anchored as found for example in locusts, cicada and lepidoptera (for review see Yack, 2004). We can even "capture" the apparent evolutionary transition of proprioceptors into dedicated auditory receptors in the act. Cockroaches possess a dual responsiveness to substrate and airborn sounds. This provides convincing evidence that auditory organs of crickets evolved from an ancestral subgenual organ (Shaw, 1994).

Although insects lack a distinct middle ear, they have nonethe-less exploited biomechanical first-order levers to enhance sound detection. Antennal receivers that exploit first-order lever mechanics-like that of the mosquito or fruit flies'-stand above all other auditory receptors in their sensitivity to angular displacement (Göpfert and Robert, 2001). Here, the end of the lever directly stretches the ciliated end of the auditory receptors. This is different to the end of the stapes in mammals that pushes, through the oval window, the fluid in the cochlea; the fluid then moves the hair bundles on top of the hair cells. Bush crickets, also developed a middle ear (Bangert et al., 1998) with characteristics similar to a 1st order lever through phase shifted motion along their tympani, which induce a motion of the fluid around the receptor cells (Montealegre- $Z$ et al., 2012; Montealegre- $Z$ and Robert, 2015). However, there are bush cricket species with tympanal ears that function like a 2 nd order levers also without a phase difference along the tympanum motion (Nowotny et al., 2010). In the taxon ensifera, which includes crickets and bush crickets, there are even basal groups (Gryllacrididae) with ears without a tympanum (middle ear) that show functional crista acustica homologs (Strauß and Lakes-Harlan, 2008).

The physical properties of sound, such as its relatively fast speed and wide diffraction, impose constrains on evolutionary solutions of auditory systems to detect and extract directional information. Given insects small size, these constraints are particularly severe. Unlike vertebrates, insects produce a poor sound shadow thus sound approaching from one side has a similar amplitude at both ears. To locate the source of a sound, many insects like crickets, bush crickets and flies exploit and amplify subtle phase differences either through biomechanical levers made of cuticle (Robert et al., 1996) or passing sound through a tracheal network. In such a network, sound reaches the tympanum, not only from the direct external route, but through a longer internal route. The extra distance traveled by the sound shifts the phase such that for each half-period of sound the tympanum is not only pulled by low pressure on the outside, it is additionally pushed by high pressure inside (visa versa for the next half-phase of sound), creating a pressure difference receiver where tympanal motion is amplified on the side nearest the sound (Michelsen et al., 1994).

\section{CONVERGENT EVOLUTION: SCULPTING SIMILAR BIOMECHANICAL FUNCTION OF EARS}

The fine-tuned ability of animal ears to discriminate frequency and maximize sensitivity relies on microscopic biomechanical specializations that couple sound-induced motion to the auditory receptors. Frequency discriminating traveling waves are a pertinent example of convergent evolution between the mammalian and Orthopteran ears (Montealegre- $Z$ et al., 2012; Udayashankar et al., 2012). In mammals, the basilar membrane shows a gradient of mass and stiffness along its length. This leads to a filter bank of damped resonators, spatial separation and gradient of auditory receptors, called tonotopy (von Békésy, 1960). The basilar membrane, the elastic membrane on which the sensory epithelium (organ of Corti) sits on, is driven by soundinduced fluid waves inside the cochlea. This creates traveling waves of the auditory epithelium, which were first observed in human cadavers (von Békésy, 1960). Traveling waves in both mammal and insect hearing organs, are much slower than aircarried sound waves. They reach velocities of about $5-25 \mathrm{~m} / \mathrm{s}$ (Udayashankar et al., 2012), more than ten times slower than in air. A consequence of the mechanical based filter bank is that tonotopic motion of the epithelium always starts in the high-frequency region, independent of the frequency of sound or where it enters (this is also the reason why bone-conduction hearing aids and headphones work).

Half a century after von Békésy's pioneering work on humanbased cochlea traveling waves (von Békésy, 1960), similar waves were recorded in the simple-ear drum like-tympanum of the locust (Windmill et al., 2005) and cicada (Sueur et al., 2006). The oval-shaped tympanic membrane is mainly composed of cuticle and the traveling wave results from the passive and nonhomogeneous anatomical properties (thickness and tension) of the tympanum (Malkin et al., 2013). Here, a thin and light part of the tympanum vibrates best at high frequencies and a thicker and more massive thick tympanum vibrates best at lower frequencies (Michelsen, 1971; Römer, 1976). These inhomogeneous properties result in a wave that travels from high frequency to low frequency (Windmill et al., 2005)just like the basilar membrane. Three discrete attachments of auditory neurons from Müller's organ are attached onto the inside of the tympanum and are stimulated best by the respective frequencies of the tympanum, permitting frequency discrimination (Jacobs et al., 1999). The elongated and linear 
arranged auditory epithelium of the bush cricket, crista acustica, resembles the biophysical properties of an uncoiled mammalian cochlea (Udayashankar et al., 2012, 2014). Like the basilar membrane of the mammalian cochlea, the crista acustica has graded changes in its stiffness and mass to make it tonotopic (Hummel et al., 2017; Olson and Nowotny, 2019). A specially evolved adaptation in hearing organs is an overrepresentation of key ecologically important frequencies along the length of epithelium, called an auditory fovea found in some mammals (Müller et al., 1992; Neuweiler and Schmidt, 1993; Kössl, 1997), birds (Köppl et al., 1993; Corfield et al., 2011) and insects (Scherberich et al., 2016, 2017).

\section{CONVERGENT EVOLUTION: MECHANISMS OF SOUND AMPLIFICATION}

Auditory transduction is localized to evolutionary-ancient membrane protrusions that have specialized to actin-based villi or microtubule based cilia in mammals and insects respectively. Mechanosensitve ion channels are located on these projections and are opened in response to sound-induced forces. Transduction channels of mammals and insects not only convert sound-induced displacements into electrical potentials but also amplify quiet sound to enhance the hearing capacity, and therefore the survival, of its owner. This final section reviews recent experiments on electrical tuning and amplification in insects and mammals and address two key areas where we expect parallel breakthroughs in our understanding of auditory transduction for mammals and insects: visualization of amplification in the insect auditory neurons and the identity of the transduction channel.

\section{Electrical Amplification in Early Vertebrates and Insects}

Electrical tuning, found in turtles, frogs and chicks (Crawford and Fettiplace, 1981; Ashmore, 1983; Lewis and Hudspeth, 1983; Fuchs et al., 1988), relies on the sinusoidal influx of cations in response to sound which then triggers the opening of other voltage gated ion channels at the base of the hair cell (Figure 2A). Voltage-dependent calcium channels in the base of the hair cell are opened in response to a transduction potential flowing through the transduction channels. Calcium flows in depolarizing the cell but calcium ions also bind and open calcium-gated potassium channels which consequently leads to potassium exiting the cell and depolarizing it. The interplay of the inflow and outflow of cations leads to an oscillation, sometimes also observed as spontaneous oscillations (Crawford and Fettiplace, 1980) and when the frequency of this oscillation matches that at which the hair cell is driven by sound it amplifies the electrical potential (Crawford and Fettiplace, 1981). Electrical amplification in hair cells is considered an evolutionary old solution restricted to non-mammalian vertebrates (Popper and Fay, 1997) and has an upper limit of about $1 \mathrm{kHz}$, which is perhaps why high-frequency hearing mammals have not exploited this mechanism. Recent work by Warren in the locust's Müller's organ has shown a lack of electrical oscillations in auditory neurons (Figure 3). The sharpness of tuning of individual auditory neurons appears the same both upon entry of cations through the transduction channels, at the apical end of the neuron, through to the spike encoding axon at the opposite end of the auditory receptor (Figure 3). These first experiments to test for electrical tuning in insect auditory neurons suggest no electrically-based mechanism is involved to sharpen or amplify acoustic signals, at least in locusts. This finding agrees with the working theory (Field and Matheson, 1998) that frequency tuning in insects is accomplished solely by the mechanical properties (mass and stiffness) of their hearing organs. Antennal hearing organs, with a set mass and stiffness, discriminate frequencies (Kamikouchi et al., 2009), so there may be more of a precedent for electrical tuning here however.

\section{Mechanical Amplification and Receptor Movements}

In mammalian and vertebrate hair cells mechanical movements that power mechanical amplification have been conventionally imaged-in outer hair cells-or movements below the optical diffraction limit ingeniously measured using a glass probe attached the stereocilia and pairs of photodiodes to localize hair bundle movements to a couple of nanometers. Based on these intricate measurements of displacements and forces directly from the receptor cilia of hair cells, and their morphology we have a good understanding of how stereocilia pivot at their base and are coupled along their axis to transduction channels to amplify quiet sound (Martin et al., 2000).

For insects, most notably two-winged insects, measurements of forces from an assemble of auditory receptors can be indirectly measured and properties of the transduction channel calculated by measuring displacements of the antennae to which they attach (Albert et al., 2007; Su et al., 2018). Despite the advancements in auditory transduction this has afforded us, the tiny and inaccessible nature of insect hearing organs and the auditory receptors themselves means we are in the dark as to howat the auditory receptor level-these movements are generated. There is general agreement that active movements that power mechanical amplification are localized to the cilium of the auditory neurons but at this stage we can not rule out other parts of the auditory neuron or other cells that compose the mechanosensory (scolopidial) unit contributing-as is the case for Prestin-based mechanical amplification in mammals, which are separate from the sensory inner hair cells.

\section{Prestin-Based Amplification}

Discovery of outer hair cell based mechanical amplification can be traced back about 40 years ago. Dallos and Harris (1978) selectively destroyed outer hair cells and found severely impaired auditory response in chinchillas. They hypothesized that outer hair cells, somehow, sensitized the sensory inner hairs cell. Then, labs reported on mechanical responses in isolated outer hair cells from the mammalian cochlea (Brownell et al., 1985; Zenner, 1986; Ashmore, 1987). In response to sound-induced 
A Electrical amplification

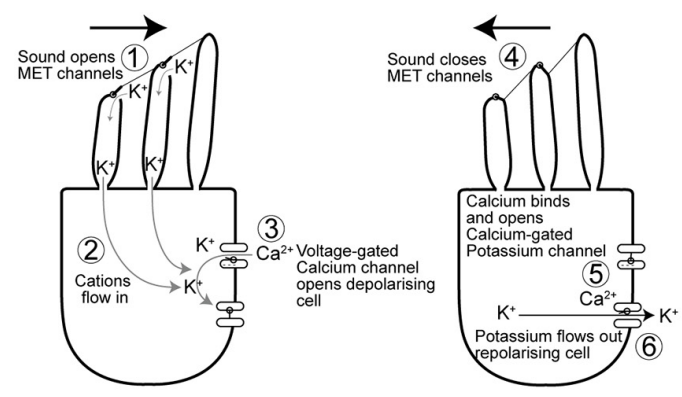

B Prestin-based amplification

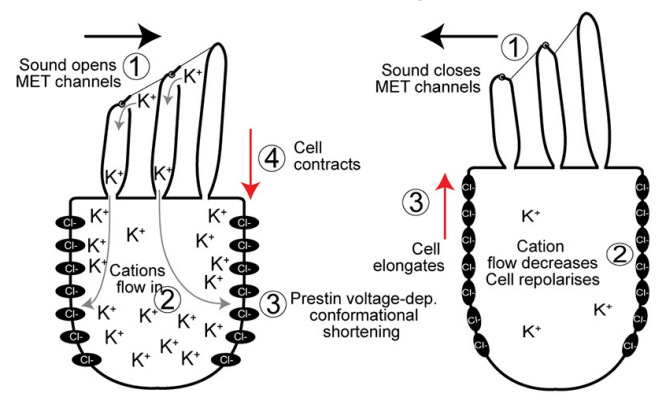

Ci

\section{Transduction channel -based amplification}

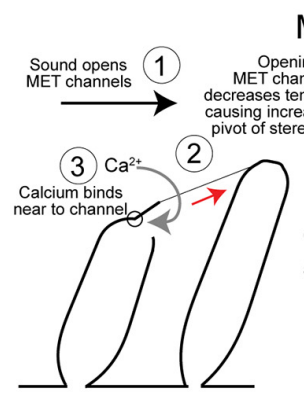

Mammal

Cii
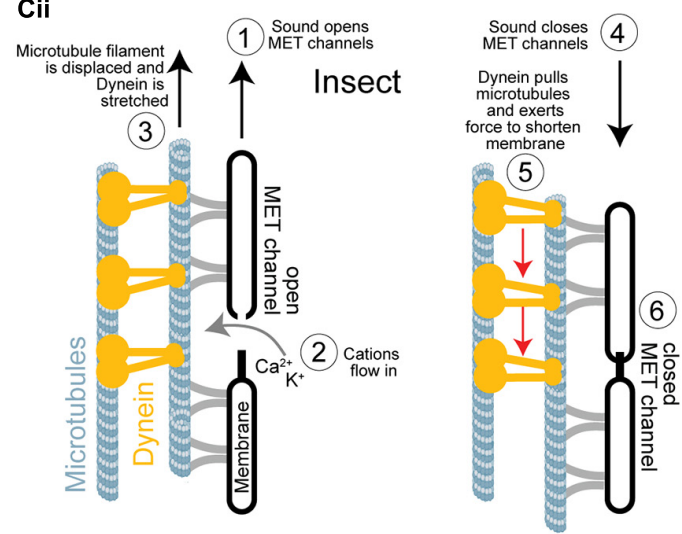

FIGURE 2 | Comparison of the three cellular mechanisms to amplify sound. (A) Electrical amplification in the frog's sacculus is based on reciprocal feedback loop created by voltage- and calcium-gated ion channels that sets up an electrical resonance which amplifies quiet sound of relatively low frequencies. (B) Prestin-based amplification of sound exclusive to mammals.

(Continued)
FIGURE 2 | Continued

Elongation and contraction of the cell body depends on the

voltage-dependant-and transduction induced-changes of the conformational state of a repurposed anion co-transporter. There is no evidence that sensory cells in insect ears undergo voltage-dependant changes in their body shape. (Ci) Simplified mechanism of hair bundle based amplification. Amplification is based on a transient reduction in stiffness as channels open causing the hair bundle to pivot further. As the transduction channels close, due to a calcium-dependant feedback, they pull the hair bundle through the tip links in the opposite direction augmenting its movement. (Cii) Proposed mechanism of amplification in insect auditory neuron cilia. Sound forces open transduction channels and causes a transient decrease in stiffness that increases movement in the direction of the force.

Dynein responds to an increase in tension by contracting pulling the microtubule filament, and the membrane housing the transduction channel, to mediate its closure. Dynein-based force production amplifies sound when in phase with it. MET, mechano-electrical transduction.

sinusoidal voltage changes, caused by the transduction potential, these cells elongate and contract to mediate rapid changes of hair cell length (Figure 2B) that push and amplify movements of a sound-induced traveling wave. This outer hair cell electromotion is facilitated by a motor protein called Prestin (Zheng et al., 2000). The motor function of this protein (protein family: SLC26) was a mammalian-specific evolutionary repurposing of an anion transporter, which existed either in the last mammalian common ancestor $\sim 200$ MYA or later in the last common ancestor of therians 130 MYA (Manley, 2000). In insects, homologs of Prestin are found (Weber et al., 2003) but without any motor function (Kavlie et al., 2015). In mammals, Prestin is essential for sensitive responses to low sound pressure levels (Liberman et al., 2002; Cheatham et al., 2004) but also for compression at high sound pressure levels (Robles and Ruggero, 2001). A complex interaction of basilar membrane motion and Prestin-induced outer hair cell motion optimize cochlea tuning (Cooper et al., 2018). During evolution, the new piezo-electric motility (Dong et al., 2002) by Prestin enabled mammals to hear ultrasonic frequencies. Here, mammals have made and exploited their own channel of communication, like some insect taxa.

Hair bundle motility amplifies and tunes their responses (Figure 2Ci). This probably existed in the primitive balance organs of the earliest vertebrates 500 MYA (Manley, 2000). Active hair bundle motility is caused by the coordinated opening and closing (adaptation) of transduction ion channels that pull to exert forces on the hair bundle, through filamentous tip links, to amplify their movements (Howard and Hudspeth, 1988). A rapid reduction in stiffness is the result of the mass opening of transduction channels pulled by filamentous tip links. The reduction in stiffness can be so severe as to become negativeit provides a force in the same direction of sound-induced forcing-thus amplifying movements (Martin et al., 2000). Rapid channel closure-known as fast adaptation-can then pull the hair bundle, through the tip links, in the opposite direction exerting a recoil force (Kennedy et al., 2003). If these channelbased forces coincide with sound-induced movement of the hair bundle it results in mechanical amplification of the hair cell displacement and therefore an amplified receptor potential. This mechanism can drive spontaneous bundle oscillations, which 


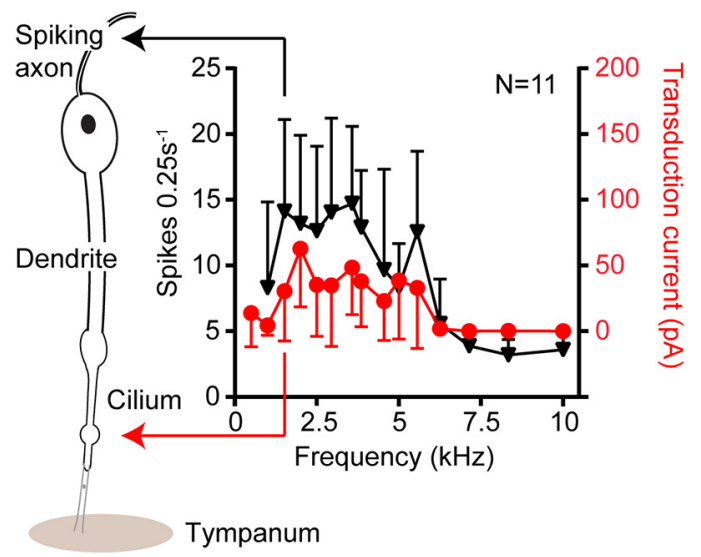

FIGURE 3 | Isolevel auditory tuning curves in response to $80 \mathrm{~dB}$ SPL from single auditory receptors of the locust ear. The black triangles are tuning curves derived from sound-induced axonal spikes at the neuron's basal end. The red circles donate tuning curves based on the transduction current at the ciliated apical end. No change in the shape of the tuning curves suggesting no electrophysiological processes, like that of reptiles to, sharpen tuning in this insect model.

were measured in the frog sacculus for example (Martin and Hudspeth, 1999). In mammals the importance of this mechanism is still discussed (Nin et al., 2012). Hair bundle-based motility based on the properties of transduction channel opening and closing is elegantly explained by a mathematical "gating spring" model first used to quantitatively describe bullfrog saccular hair bundle dynamics (Howard and Hudspeth, 1988).

Active hearing in insects was first shown in mosquitos and Drosophila and was later shown to have remarkable parallels with hair bundle motility. Sound-receiving antennal receivers were discovered to oscillate spontaneously, but under $\mathrm{CO}_{2}$ indcued hypoxia these active oscillations disappeared (Göpfert and Robert, 2001, 2002). Later, the first insect with tympanal ears was shown to exhibit spontaneous oscillations that disappeared upon death (Mhatre and Robert, 2013). An interaction of mechanotransduction channels and motor proteins in the sensory cells are hypothesized to be the basis of these oscillations (Nadrowski et al., 2008). Most striking of all is that, despite separate $\sim 600$ million year evolutionary trajectories, the "gatingspring" model, first used to describe frog hair bundle movements also quantitatively explains the mechanics of antennal soundreceivers-ears - of fruit flies and mosquitoes (Albert et al., 2007; Su et al., 2018). This is a spectacular illustration of convergent evolution of two hearing systems, with very different architecture, that have combined the gating of transduction channels with mechanical amplification of sound. Key in the gating spring model is adaptation and rapid closure of the channel after opening. In insects a dynein motor is hypothesized to rapidly close the channels after opening (Karak et al., 2015). However, for hair cell receptors $\mathrm{Ca}^{2+}$ binding close to the channel complex is thought to conformationally close it (Figure 2Ci; Peng et al., 2013; Corns et al., 2014) and this might also be the case for insect auditory cilia. The energy for this process presumably comes from the very steep electrical gradient of $\sim 130 \mathrm{mV}$ (von Békésy, 1952; Russell and Sellick, 1978) across the hair cells. A steep electrochemical gradient is shown to be the case for some insect mechanoreceptors (Thurm and Küppers, 1980) and assumed to be so for auditory neurons of insects (Kavlie and Albert, 2013; Warren and Matheson, 2018). In lower vertebrates, such as turtles and bullfrogs, slow adaptation of the channel maintains an optimal tension and open probability of the channel and is powered by myosin motors anchored to the actin cytoskeleton (Gillespie and Cyr, 2004; Stauffer et al., 2005). As insect auditory cilia have a microtubule cytoskeleton bearing dynein arms (Karak et al., 2015), channel closing in insects is thought to be powered by dynein (see for review Göpfert and Robert, 2008; Göpfert and Hennig, 2016; Figure 2Cii). Further supporting dynein's role in transduction, are measurements of the temperature dependence of spontaneous oscillations in mosquitoes (Warren et al., 2010), and distortion-product otoacoustic emissions in locusts (Möckel et al., 2012) both hallmarks of the transduction process. The temperature dependence of biological processes gives information about the chemical reactions that produce them. In this case the activation energy measured for both spontaneous oscillations and distortion-product otoacoustic emissions matched that of the enzyme dynein ATPase, which is hypothesized to provide the energy for mechanical amplification.

\section{MODE OF TRANSDUCTION - CLOSING THE GAP ON THE IDENTITY OF THE TRANSDUCTION ION CHANNEL IN MAMMALS AND INSECTS}

Over the past 40 years a fascinating and persistent search for the mammalian transduction channel has captured the imagination of sensory biologists. This dramatic roller-coaster of discovery and dismissal of various promising hair cell transduction channel candidates has led to today's more tentative approach to claims that the channel has been found. One realization is that the channel works in a complex with other membrane proteins, which exist in different isoforms-quelling the idea of the transduction channel and setting out a longer more gradual journey to discover of all the interacting components. About 20 years ago insects jumped into search for its own auditory transduction channel, powered by the genetic versatility of the fruit fly. As it will become clear in the next paragraphs, both research fields have made remarkable progress, but it is those working on the mammalian hair cell transduction channel that appear to be cautiously closing in on the channel identity.

In mammals, tip links, composed of cadherin 23 at their apical end and protocadherin 15 at their lower end (Kazmierczak et al., 2007), orientate in one direction and connect adjacent stereovilli in hair bundles (Figure 4A; Hudspeth, 1985). In zebrafish protocadherin 15 connects to a candidate protein of the hair cell transduction channel, a transmembrane channellike channel (TMCs) (Maeda et al., 2014). In contrast, sensory cells of insect ears have only one ciliate hair and tip links are not present (Figure 4B; Kavlie and Albert, 2013). Therefore, 


\section{A Mammalian hair cells B Insect auditory neuron}

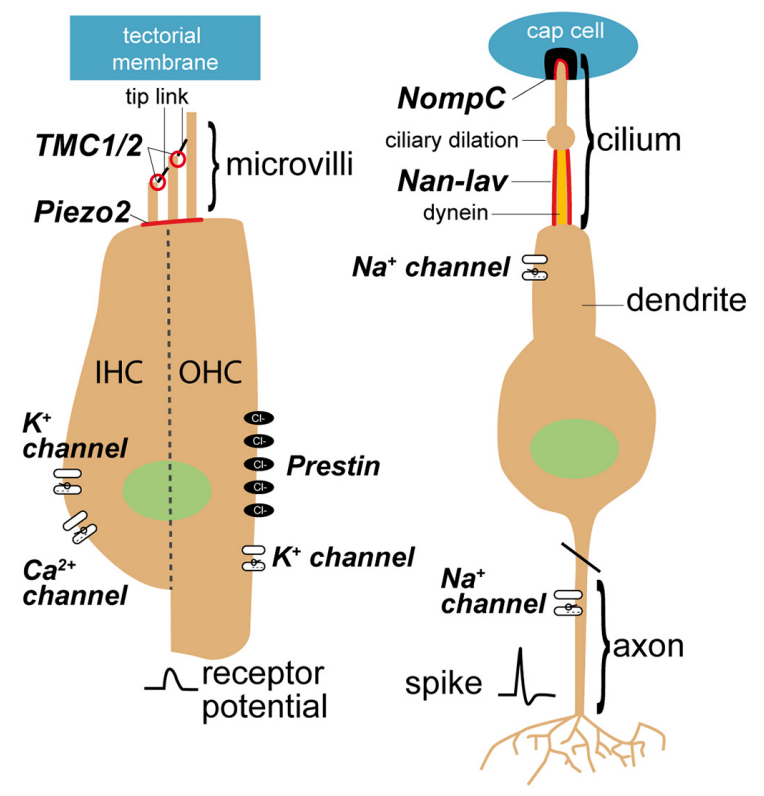

FIGURE 4 | Sensory cells in mammals (A) and insects (B) and mechanosensitive channels that are involved in the transduction process. Mechanosensitive channels in mammals belong to the transmembrane channel-like proteins (TMCs), whereas mechanosensitive channels in the insect ears are members of the transient receptor potential (TRP) family (see for review Jin et al., 2020). TMC are believed to evolved from TRP channels (Saier, 2016). Nan-lav, nanchung-inactive; NompC, no mechanoreceptor potential C. the question arises how in an insect ear the transduction channels are opened without the connection by tip links. In insects, the protein structure of the mechanosensitive channel protein NompC (Jin et al., 2017) is well known. The other contender for the auditory transduction channel, NanchungInactive, not. The interplay and role of these channels is still under discussion (Albert and Göpfert, 2015; Hummel et al., 2016). However, in mammals, the position and function of the transduction channel is well characterized (Beurg et al., 2009; Peng and Ricci, 2011; Ó Maoiléidigh and Ricci, 2019), but the involved proteins and their interplay are being established (Qiu and Müller, 2018).

The first candidate for the hair cell transduction channel were epithelial sodium channels $(\mathrm{ENaC})$ because they were localized to the stereovilli tips (Hackney et al., 1992), had isoforms in the chick cochlea (Killick and Richardson, 1997) and homologous MEC genes in C. elegans, when knocked out, had mechanosensory defects (O'Hagan et al., 2005). Despite such early promise the selectivity of ENaC's to $\mathrm{Na}^{+}$and $\mathrm{Ca}^{2+}$ were too high and low respectively compared to that measured in hair cells (Kellenberger and Schild, 2002) so were the first to be ruled out. At the turn of the century, a decade after the first transient receptor potential (TRP) channels, required for vision, were discovered in Drosophila (Hardie and Minke, 1992), mechanically sensitive TRP channels were being discovered and characterized across the animal kingdom from flies and zebrafish to frogs and worms (Walker et al., 2000; Sidi et al., 2003; Shin et al., 2005; Li et al., 2006). As two TRP channels had been identified essential for hearing in Drosophila (Walker et al., 2000), at this stage, it was thought possible that, for both insects and mammals, TRP channels were the transduction channel. The accumulating widespread sensory functions of TRPs across animals (Madrid and Bacigalupo, 2015) made them all the more convincing and, for mammals, there was one outstanding candidate, TRPA1 (Corey et al., 2004). Transduction currents were severely affected, sometimes absent, in mice with TRPA1 knockdowns, TRPA1 localized to the hair bundle tips, where the channels are, and the start of expression coincides with hearing. Disappointingly, it was later shown that hair cells with knockout of TRPA1 have normal transduction currents (Kwan et al., 2006), they were dismissed and the search continued.

Adding to an already complex system, a distinct mechanicallyelicited electrophysiological current (reverse-polarity current) was discovered that manifested in hair cells even when tip links are severed (Marcotti et al., 2014). This current was proposed to be a candidate for the transduction channel (Beurg and Fettiplace, 2017) but later electrophysiological characterization strongly suggested they were different channels (Marcotti et al., 2014). This reverse polarity current was discovered to be carried by Piezo channels (Wu et al., 2017) already identified to have diverse roles in touch sensation (Gottlieb, 2017). Thus, Piezo could be the penultimate candidate for the hair cell transduction channel, expressed in the cochlea (Wu et al., 2017), if the latest candidate-transmembrane channel-like protein (TMC) channels-withstand the battery of tests it is currently undertaking to win the race (Pan et al., 2018). Two transmembrane channels isoforms (TMC1 and TMC2) and associated proteins are the leading contenders for core components for the transduction channel (Corey et al., 2019; Figure 4A). As well as localization to the site of the channel, TMC2 expression coinciding with onset of mechanotransduction (Kawashima et al., 2011) and multiple pore mutations predicted to alter the channel's ion selectivity and binding with the blocker dihydrostreptomycin do so (Pan et al., 2013, 2018; Corns et al., 2016). TMC orthologs are functionally conserved in Drosophila larvae for touch sensation but the scattering of TMC expression in auditory neurons suggests that TMCs are not the insect auditory transduction channel (Guo et al., 2016).

Two outstanding candidates for the insect transduction channel were discovered with forward genetic screens (Kernan et al., 1994; Kim et al., 2003; Gong et al., 2004). These transduction channels are: NompC and Nanchung-Inactive (Figure 4B). Both, NompC and Nanchung-Inactive, belong to the TRPN and TRPV sub families of the TRP superfamily of sensory ion channels and localize to the tip and proximal part of the cilium respectively (Gong et al., 2004; Liang et al., 2010). Although NompC forms a bone fide mechanotransduction channel, even when expressed in heterologous cells or ectopically (Gong et al., 2013; Zhang et al., 2015), intracellular recordings of the transduction current support Nanchung-Inactive as the transduction channel (Lehnert et al., 2013; Warren and Matheson, 2018). 
NompC connects the membrane to the microtubule cytoskeleton (Howard and Bechstedt, 2004; Jin et al., 2017) where the cilia are attached to the cap, most clearly shown for cuticle strain-sensitive campaniform receptors (Zhang et al., 2015). This is because the 29 ankyrin repeats of each NompC ion channel form a helical spring (Michaely et al., 2002; Jin et al., 2020), are compliant structures and absent when NompC is knocked out (Liang et al., 2013). Connection of the cap to the ciliary tip membrane is through a membrane-embedded filamentous extracellular matrix protein, including NompA (Chung et al., 2001). NompA could also directly gate the transduction channels of insect auditory neurons, like the vertebrate tip link, because the leading candidate mechanotransduction ion channel NompC also localizes to ciliary tip (Lee et al., 2010).

Two competing models exists to explain the respective functions of NompC and Nanchung-Inactive (Göpfert et al., 2006; Lehnert et al., 2013; Albert and Göpfert, 2015). The NompC hypothesis assumes that NompC, at the tip of the cilium, is the primary transduction ion channel and Nanchung-Inactive, propagates the transduction potential down the cilium, like an action potential (Göpfert et al., 2006). NompC produces forces, by channel gating, that move the antennae. The origin of these forces are thought to be due to the mechanical forces produced by dynein (Shingyoji et al., 1998; Karak et al., 2015) or due to a conformation change of the channels gate powered by the steep electrochemical gradient across the channel (Mhatre, 2015). In this model NompC produced force is regulated by NanchungInactive. NompC is a clear frontrunner for the channel. It forms a mechanotransduction ion channel in heterologous cells, the permeability of which can be altered through pore mutations (Yan et al., 2013). It functions as a mechanotransducer when expressed ectopically in non-mechanically sensitive neurons (Yan et al., 2013) and is a bone fide mechanotransduction ion channel in other mechanoreceptors (Gong et al., 2013). When Nanchung or Inactive are knocked out, spontaneous active motility of the antennae increases 10-fold, explained by the model's lack of feedback regulation by Nanchung-Inactive. Whereas mutations in NompC lead to a reduction in the compound potential recorded from the fly Johnston's organ and total loss of mechanical amplification (Göpfert et al., 2006). When NompC is knocked out there remains a small sound-evoked compound potential from Johnston's organ. The NompC model accounts for this as being due to gravity dedicated neurons that weakly respond to sound (Kamikouchi et al., 2009). Because mechanical amplification of the auditory neurons depends on channel gating-as predicted by the gating spring model-a lack of amplification would be predicted when the mechanotransduction channel is mutated, which supports NompC.

Evidence against NompC stems from intracellular recordings of the sound-evoked current flowing though the mechanotransduction ion channel. Here no potentials are detected in NompC mutants or when Nanchung-Inactive are pharmacologically impaired (Lehnert et al., 2013; Warren and Matheson, 2018). As such, the Nanchung-Inactive hypothesis (Lehnert et al., 2013) states that NompC regulates the tension delivered to the true mechanotransduction channel NanchungInactive. The only direct intracellular voltage-controlled recordings in locust auditory neurons failed to show any voltage activation of Nanchung-Inactive (Warren and Matheson, 2018), casting doubts on the electrical propagation role predicted by the NompC model, at least in morphologically similar orthopteran auditory receptors. Other recent work on age-related hearing decline in Drosophila also adds to our understanding of the respective roles of NompC and NanchungInactive. When the transcription factor, Onecut, involved in sensory organ development and maintenance, is knocked down auditory transduction is nearly completely lost-including the antennae's ability to mechanically amplify quiet sound (Keder et al., 2020). In Onecut knockdown, both, Nanchung and Inactive expression levels are decreased, but NompC expression levels are unchanged, suggesting that Nanchung and Inactive are more critical for transduction than NompC (Keder et al., 2020). NompC is also expressed and essential for the function of two other non-auditory mechanoreceptor types-bristle and campaniform-and when genetically knocked out results in a decrease of mechanotransduction (Kernan et al., 1994; Liang et al., 2010). However, transient knockdown of mechanotransduction channel candidates in cockroach, using RNAi, resulted in reduction of the bristle receptor response only for Nanchung and Inactive but not for NompC (Hennenfent et al., 2020). Thus, it appears that Nanchung-Inactive are, at least, drawing level with NompC as contenders for the auditory transduction channel in insects. NompC, no doubt, has a critical role in auditory transduction, especially to coupling forces to the cilium, but previous work on NompC has relied of germline genetic mutations of NompC, which makes it hard to discern between a developmental phenotype and a functional phenotype. The crucial experiment that will break the two contender deadlock are direct recordings of the transduction current (Warren and Matheson, 2018) with pore mutations of the channel candidates.

In insects, channel gating is determined by the relative stretch of the cellular membrane and microtubule cytoskeleton. However, the effective stimulus to open transduction channels in the cilium is largely speculative and based on the morphology of the cilium; is it pull along the ciliary axis, bending or tilting for instance? The two contenders for the insect auditory transduction channel, NompC and Nanchung-Inactive are positioned along opposing sides of a dilation in the sensory dendrite (Figure 4B). NompC is located at the ciliary tip above the dilation (Liang et al., 2011) and Nanchung-Inactive located at the proximal dendrite below the dilation (Kim et al., 2003). Although dynein is only located below the dilation it could be coupled to either prospective channel; longitudinally through the microtubule cytoskeleton, that passes through a ciliary dilation, for NompC or through a possible direct connection for Nanchung-Inactive (Field and Matheson, 1998) through structures termed microtubule integrated cones (Thurm et al., 1983). In either scheme stretch-activation of dynein is necessary for any dynein-based force production in cilia. It was suggested that pull along the axis of the cilium is the effective stimulus of all chordotonal organs (Field and Matheson, 1998; Todi et al., 2004). This is based on (i) the rigid channel or receptor lymph space maintained by the scolopale cell and its actin cytoskeleton, 
(ii) connections of the cilium are commonly in line with the ciliary axis, and (iii) the cilium is long and slender. Recent work on bush crickets by Hummel et al. (2016), however, shows that tilt of the ciliary tip that is the most effective way to stimulate the chordotonal sensory cell. Here the phase delay of the traveling wave, where the tilt of the ciliary tip is maximal, leads to the largest neural response.

Nanometer displacement of hair cell stereocilia has been resolved through an ingenious projection of the shadow of a glass probe, attached to the stereocilia tips, onto a pair of photodiodes (Howard and Hudspeth, 1988). The nanometer displacement of the glass probe, due to stereocilia movement, can be calculated from the proportion of photons blocked on each adjacent photodiode. In insects it may be possible to optically interpret ciliary movements by projecting the cilium directly onto adjacent photosensors and measure their proportional activation. Such an approach seems impossible in flies, mosquitoes and one species of tree cricket where mechanical amplification has been proven (Göpfert and Robert, 2001, 2002; Mhatre and Robert, 2013) due to the inaccessible nature of their hearing organs. However, such an approach would be feasible in the locust's Müller's organ and perhaps other non-model insects. It could be argued, only cilia in insects known to provide mechanical amplification would be motile but the inability to detect mechanical amplification should not rule out the absence of ciliary movements. Dynein is present in the cilia of all chordotonal organ neurons so far examined. Thus, it has a role, active or otherwise, in chordotonal organ transduction. Until measured directly ciliary movements are purely speculative but we predict that the cilium would twist. This is because the dynein-tubulin connections follow a ring formation and forces could only be generated through relative movement between adjacent microtubule doublets. Other cilia with $9 \times 2+0$ arrangement rotate their free apical end clockwise (Nonaka et al., 1998). Imaging the auditory receptors themselves has provided a deeper and powerful understanding of mechanotransduction in hair cells that has accelerated understanding. We predict that

\section{REFERENCES}

Albert, J. T., and Göpfert, M. C. (2015). Hearing in Drosophila. Curr. Opin. Neurobiol. 34, 79-85.

Albert, J. T., Nadrowski, B., and Göpfert, M. C. (2007). Mechanical signatures of transducer gating in the Drosophila ear. Curr. Biol. 17, 1000-1006. doi: 10.1016/j.cub.2007.05. 004

Allin, E. F., and Hopson, J. A. (1992). "Evolution of the auditory system in Synapsida ("Mammal-like reptiles" and primitive mammals) as seen in the fossil record," in The Evolutionary Biology of Hearing, eds D. B. Webster, A. N. Popper, and R. R. Fay (New York, NY: Springer), 587-614. doi: 10.1007/978-1-46122784-7_37

Arendt, D., and Wittbrodt, J. (2001). Reconstructing the eyes of Urbilateria. Philos. Trans. R. Soc. Lond. B Biol. Sci. 356, 1545-1563. doi: 10.1098/rstb.2001.0971

Asai, Y., Pan, B., Nist-Lund, C., Galvin, A., Lukashkin, A. N., Lukashkina, V. A., et al. (2018). Transgenic Tmc2 expression preserves inner eat cells and vestibular function in mice lacking Tmcl. Sci. Rep. 8:12124. doi: 10.1038/ s41598-018-28958- $x$ such a breakthrough will have similar repercussions for insect auditory transduction.

As the insect labs push forward to find the channel the search for the mammalian transduction channel has gifted some key lessons. For instance, as many mammalian channel candidates fell to the road side, we must be open to the possibility that neither NompC nor Nancung-Inactive is the hearing channel for insects. For mammals, it is a channel complex as opposed to a single protein that is required for auditory transduction and there may well be different isoforms to account for different conductivities along the cochlea (Beurg et al., 2018). Further complicating matters is the redundancy of TMC channels; knockout of TMC1 results in TMC2 taking up its function (Asai et al., 2018). Thus, even if a knockout of a single gene has no effect it may still be the channel. Our forlorn hope is that the insect hearing channel is a simple one channel solution and that it is either NompC or Nanchung-Inactive but our sneaking suspicion is that it will not be so simple.

\section{AUTHOR CONTRIBUTIONS}

Both authors developed the concept of the publication and wrote the publication.

\section{FUNDING}

This work was funded by the Royal Society University Research Fellowship awarded to BW and by the German Research Foundation (DFG, No 841/10-1).

\section{ACKNOWLEDGMENTS}

Tom Matheson and Stefan Schöneich gave feedback and comments on manuscript draft. We would like to thank Sci Hub for access to papers, the absence of this server would have made this review not possible.

Ashmore, J. F. (1983). Frequency tuning in a frog vestibular organ. Nature 304, 536-538. doi: 10.1038/304536a0

Ashmore, J. F. (1987). A fast motile response in guinea-pig outer hair cells: the cellular basis of the cochlear amplifier. J. Physiol. 388, 323-347. doi: 10.1113/ jphysiol.1987.sp016617

Baird, I. L. (1974). "Anatomical features of the inner ear in submammalian vertebrates," in Auditory System. Handbook of Sensory Physiology, Vol. 5/1, eds W. D. Keidel and W. D. Neff (Berlin: Springer-Verlag), 159-212. doi: 10.1007/ 978-3-642-65829-7_6

Bangert, M., Kalmring, K., Sickmann, T., Stephen, R., Jatho, M., and Lakes-Harlan, R. (1998). Stimulus transmission in the auditory receptor organs of the foreleg of bushcrickets (Tettigoniidae). I. The role ofthe tympana. Hear. Res. 115, 27-38. doi: 10.1016/S0378-5955(97)00177-9

Berney, C., and Pawlowski, J. (2006). A molecular time-scale for eukaryote evolution recalibrated with the continuous microfossil record. Proc. Biol. Sci. 273, 1867-1872. doi: 10.1098/rspb.2006.3537

Béthoux, O., André, N., Lapeyrie, J., and Gand, G. (2003). The Permostridulidae fam. n. (Panorthoptera), a new enigmatic insect family from the Upper Permian of France. Eur. J. Entomol. 100, 581-585. doi: 10.14411/eje.2003.087 
Beurg, M., and Fettiplace, R. (2017). PIEZO2 as the anomalous mechanotransducer channel in auditory hair cells. J. Physiol. 595, 7039-7048. doi: 10.1113/JP274996

Beurg, M., Cui, R., Goldring, A. C., Ebrahim, S., Fettiplace, R., and Kachar, B. (2018). Variable number of TMC1-dependant mechanotransducer channels underlie tonotopic conductance gradients in the cochlea. Nat. Commun. 9:2185. doi: 10.1038/s41467-018-04589-8

Beurg, M., Fettiplace, R., Nam, J. H., and Ricci, A. J. (2009). Localization of inner hair cell mechanotransducer channels using high-speed calcium imaging. Nat. Neurosci. 12, 553-558. doi: 10.1038/nn.2295

Beznosov, P. A., Clack, J. A., Lukševičs, E., Ruta, M., and Ahlberg, P. E. (2019). Morphology of the earliest reconstructable tetrapod Parmastega aelidae. Nature 574, 527-531. doi: 10.1038/s41586-019-1636-y

Brownell, W. E., Bader, C. R., Bertrand, D., and de Ribaupierre, Y. (1985). Evoked mechanical responses of isolated cochlear outer hair cells. Science 227, 194-196. doi: 10.1126/science. 3966153

Burighel, P., Lane, N. J., Fabio, G., Stefano, T., Zaniolo, G., Carnevali, M. D., et al. (2003). Novel, secondary sensory cell organ in ascidians: in search of the ancestor of the vertebrate lateral line. J. Comp. Neurol. 461, 236-249. doi: $10.1002 /$ cne. 10666

Carroll, S. B., Grenier, J. K., and Weatherbee, S. D. (2001). From DNA to Diversity: Molecular Genetics and the Evolution of Animal Design. Hoboken, NJ: WileyBlackwell.

Cheatham, M. A., Huynh, K. H., Gao, J., Zuo, J., and Dallos, P. (2004). Cochlear function in prestin knockout mice. J. Physiol. 560, 821-830.

Chung, Y. D., Zhu, J., Han, Y., and Kernan, M. J. (2001). nompA encodes a PNSspecific, ZP domain protein required to connect mechanosensory dendrites to sensory structures. Neuron 29, 415-428. doi: 10.1016/s0896-6273(01)00215-x

Clack, J. A. (1983). The stapes of the coal measures embolomere Pholiderpeton scutigerum Huxley (Amphibia: Anthracosauria) and otic evolution in early tetrapods. Zool. J. Linn. Soc. 79, 121-148. doi: 10.1111/j.1096-3642.1983. tb01163.x

Clack, J. A. (1992). "The stapes of Acanthostega gunnari and the role of the stapes in early tetrapods," in The Evolutionary Biology of Hearing, eds D. B. Webster, A. N. Popper, and R. R. Fay (New York, NY: Springer), 405-420. doi: 10.1007/978-1-4612-2784-7_24

Clack, J. A., Ahlberg, P. E., Finney, S. M., Dominquez, A. P., Robinson, J., and Ketcham, R. A. (2003). A uniquely specialized ear in a very early tetrapod. Nature 425, 65-69. doi: 10.1038/nature01904

Clack, J. A., and Allin, E. (2000). "The evolution of single and multiple-ossicle ears in fishes and tetrapods," in Evolution of the Vertebrate Auditory System, eds G. A. Manley, R. R. Fay, and A. N. Popper (New York, NY: Springer), 128-163. doi: 10.1007/978-1-4419-8957-4_5

Cooper, G. M. (2000). "The origin and evolution of cells," in The Cell: A Molecular Approach, 2nd Edn, ISBN: 0878931066 (Sunderland, MA: Sinauer Associates Inc.).

Cooper, N. P., Vavakou, A., and van der Heijden, M. (2018). Vibration hotspots reveal longitudinal funneling of sound-evoked motion in the mammalian cochlea. Nat. Commun. 9:3054

Corey, D. P., Akyuz, N., and Holt, J. R. (2019). Function and dysfunction of TMC channels in inner ear hair cells. Cold Spring Harb. Perspect. Med. 9:a033506. doi: 10.1101/cshperspect.a033506

Corey, D. P., García-Añoveros, J., Holt, J. R., Kwan, K. Y., Lin, S. Y., Vollrath, M. A., et al. (2004). TRPA1 is a candidate for the mechanosensitive transduction channel of vertebrate hair cells. Nature 432, 723-730. doi: 10.1038/nature03066

Corfield, J., Kubke, M. F., Parsons, S., Wild, J. M., and Köppl, C. (2011). Evidence for an auditory fovea in the New Zealand kiwi (Apteryx mantelli). PLoS One 6:e23771. doi: 10.1371/journal.pone.0023771

Corns, L. F., Johnson, S. L., Kros, C. J., and Marcotti, W. (2014). Calcium entry into stereocilia drives adaptation of the mechanoelectrical transducer current of mammalian cochlear hair cells. Proc. Natl. Acad. Sci. U.S.A. 111, 14918-14923. doi: 10.1073/pnas.1409920111

Corns, L. F., Johnson, S. L., Kros, C. J., and Marcotti, W. (2016). Tmcl point mutation affects $\mathrm{Ca} 2+$ sensitivity and block by dihydrostreptomycin of the mechanoelectrical transducer current of mouse outer hair cells. J. Neurosci. 36, 336-349. doi: 10.1523/JNEUROSCI.2439-15.2016

Crawford, A. C., and Fettiplace, R. (1980). The frequency selectivity of auditory nerve fibres and hair cells in the cochlea of the turtle. J. Physiol. 306, 79-125. doi: 10.1113/jphysiol.1980.sp013387
Crawford, A. C., and Fettiplace, R. (1981). An electrical tuning mechanism in turtle cochlear hair cells. J. Physiol. 312, 377-412. doi: 10.1113/jphysiol.1981. sp013634

Dallos, P., and Harris, D. M. (1978). Properties of auditory nerve responses in the absence of outer hair cells. J. Neurophysiol. 41, 365-383. doi: 10.1152/jn.1978. 41.2.365

de Robertis, E. M., and Sasai, Y. A. (1996). A common plan for dorsoventral patterning in Bilateria. Nature 380, 37-40. doi: 10.1038/380037a0

Dong, X. X., Ospeck, M., and Iwasa, K. H. (2002). Piezoelectric reciprocal relationship of the membrane motor in the cochlear outer hair cell. Biophys. J. 82, 1254-1259. doi: 10.1016/s0006-3495(02)75481-7

Doolittle, R. F., Feng, D. F., Tsang, S., Cho, G., and Little, E. (1996). Determining divergence times of the major kingdoms of living organisms with a protein clock. Science 271, 470-477. doi: 10.1126/scie nce. 271

Douzery, E. J., Snell, E. A., Bapteste, E., Delsuc, F., and Philippe, H. (2004). The timing of eukaryotic evolution: does a relaxed molecular clock reconcile proteins and fossils? Proc. Natl. Acad. Sci. U.S.A. 101, 15386-15391. doi: 10. 1073/pnas.0403984101

Doyle, A. J. (2012). Molecular and fossil evidence on the origin of angiosperms. Annu. Rev. Earth Planet. Sci. 40, 301-326. doi: 10.1146/annurev-earth-042711105313

Field, L. H., and Matheson, T. (1998). "Chordotonal organs of insects," in Advances in Insect Physiology, Vol. 27, ed. P. D. Evans (Cambridge, MA: Academic), $2-230$.

Forey, P., and Janvier, P. (1994). Evolution of the early vertebrates. Am. Sci. 82, 554-566.

Fuchs, P. A., Nagal, T., and Evans, G. (1988). Electrical tuning in hair cells isolated from the chick cochlea. J. Neurosci. 8, 2460-2467. doi: 10.1523/jneurosci.0807-02460.1988

Fullard, J. H., and Yack, J. E. (1993). The evolutionary biology of insect hearing. Trends Evol. Ecol. 8, 248-252. doi: 10.1016/0169-5347(93)90200-9

Gaetano, L. C., and Abdala, F. (2015). The stapes of Gomphodont cynodonts: insights into the middle ear structure of non-mammaliaforms cynodonts. PLoS One 10:e0131174. doi: 10.1371/journalpone.0131174

Garcia, A. K., Schopf, J. W., Yokobori, S.-I., Akanuma, S., and Yamagishi, A. (2017). Reconstructed ancestral enzymes suggest long-term cooling of Earth's photic zone since the Archean. Proc. Natl. Acad. Sci. U.S.A. 114, 4619-4624. doi: $10.1073 /$ pnas. 1702729114

Gillespie, P. G., and Cyr, J. L. (2004). Myosin-1c, the hair cell's adaptation motor. Annu. Rev. Physiol. 66, 521-545. doi: 10.1146/annurev.physiol.66. 032102.112842

Gong, J., Wang, Q., and Wang, Z. (2013). NOMPC is likely a key component of Drosophila mechanotransduction channels. Eur. J. Neurosci. 38, 2057-2064. doi: 10.1111/ejn.12214

Gong, Z., Son, W., Chung, Y. D., Kim, J., Shin, D. W., McClung, C. A., et al. (2004). Two interdependent TRPV channel subunits, inactive and Nanchung, mediate hearing in Drosophila. J. Neurosci. 24, 9059-9066. doi: 10.1523/JNEUROSCI. 1645-04.2004

Göpfert, M. C., Albert, J. T., Nadrowski, B., and Kamikouchi, A. (2006). Specification of auditory sensitivity by Drosophila TRP channels. Nat. Neurosci. 9, 999-1000. doi: 10.1038/nn1735

Göpfert, M. C., and Hennig, R. M. (2016). Hearing in insects. Annu. Rev. Entomol. 61, 257-276. doi: 10.1146/annurev-ento-010715-023631

Göpfert, M. C., and Robert, D. (2001). Active auditory mechanics in mosquitoes. Proc. R. Soc. B 258, 333-339. doi: 10.1098/rspb.2000.1376

Göpfert, M. C., and Robert, D. (2002). Motion generation by Drosophila mechanosensory neurons. Proc. Natl. Acad. Sci. U.S.A. 100, 5514-5519. doi: 10.1073/pnas. 0737564100

Göpfert, M. C., and Robert, D. (2008). "Active processes in insect hearing," in Active Processes and Otoacoustic Emissions in Hearing, eds G. A. Manley, R. R. Fay, and A. N. Popper (New York, NY: Springer), 191-209. doi: 10.1007/978- 0-38771469-1_6

Gottlieb, P. A. (2017). A tour de force: the discovery, properties, and function of piezo channels. Curr. Top. Membr. 79, 1-36. doi: 10.1016/bs.ctm.2016.11.007

Graybeal, A., Rosowski, J. J., Ketten, D. R., and Crompton, A. W. (1989). Inner-ear structure in Morganucodon, an early Jurassic mammal. Zool. J. Linn. Soc. 96, 107-117. doi: 10.1111/j.1096-3642.1989.tb01823.x 
Grothe, B., and Pecka, M. (2014). The natural history of sound localization in mammals - a story of neuronal inhibition. Front. Neural Circuits 8:116. doi: 10.3389/fncir.2014.00116

Gu, J. J., Montealegre-Z, F., Robert, D., Engel, M. S., Qiao, G. X., and Ren, D. (2012). Wing stridulation in a Jurassic katydid (Insecta, Orthoptera) produced low-pitched musical calls to attract females. Proc. Natl. Acad. Sci. U.S.A. 109, 3868-3873. doi: 10.1073/pnas.1118372109

Guo, Y., Wang, Y., Zhang, W., Meltzer, S., Zanini, D., Yu, Y., et al. (2016). Transmembrane channel-like (tmc) gene regulates Drosophila larval locomotion. Proc. Natl. Acad. Sci. U.S.A. 113, 7243-7248. doi: 10.1073/pnas. 1606537113

Hackney, C. M., Furness, D. N., Benos, D. J., Woodley, J. F., and Barratt, J. (1992). Putative immunolocalization of the mechanoelectrical transduction channels in mammalian cochlear hair cells. Proc. Biol. Sci. 248, 215-221. doi: 10.1098/rspb. 1992.0064

Han, G., Mao, F., Bi, S., Wang, Y., and Meng, J. (2017). A Jurassic gliding euharamiyidan mammal with an ear of five auditory bones. Nature 551, 451456. doi: $10.1038 /$ nature 24483

Hardie, R. C., and Minke, B. (1992). The trp gene is essential for a light-activated Ca2+ channel in Drosophila photoreceptors. Neuron 8, 643-651. doi: 10.1016/ 0896-6273(92)90086-s

Hedwig, B. (2014). Insect Hearing and Acoustic Communication. Berlin: Springer.

Hejnol, A., and Martindale, M. Q. (2008). Acoel development supports a simple planula-like urbilaterian. Philos. Trans. R. Soc. Lond. B Biol. Sci. 363, 1493-1501. doi: $10.1098 /$ rstb.2007.2239

Hennenfent, A., Liu, H., Torkkeli, P. H., and French, A. S. (2020). RNA interference supports a role for Nanchung-Inactive in mechanotransduction by the cockroach, Periplaneta Americana, tactile spine. Invert. Neurosci. 20:1. doi: 10.1007/s10158-019-0234-x

Hetherington, T. E. (1992). The effects of body size on functional properties of middle ear systems of anuran amphibians. Brain Behav. Evol. 39, 133-142. doi: $10.1159 / 000114111$

Hildebrand, M., and Goslow, G. (1995). Analysis of Vertebrate Structure. Hoboken, NJ: Wiley.

Howard, J., and Bechstedt, S. (2004). Hypothesis: a helix of ankyrin repeats of the NOMPC- TRP ion channel is the gating spring of mechanoreceptors. Curr. Biol. 14, R224-R226. doi: 10.1016/j.cub.2004.02.050

Howard, J., and Hudspeth, A. J. (1988). Compliance of the hair bundle associated with gating of mechanoelectrical transduction channels in the bullfrog's saccular hair cell. Neuron 1, 189-199. doi: 10.1016/0896-6273(88)90139-0

Hudspeth, A. J. (1985). The cellular basis of hearing: the biophysics of hair cells. Science 230, 745-752. doi: 10.1126/science.2414845

Hummel, J., Kössl, M., and Nowotny, M. (2017). Morphological basis for a tonotopic design of an insect ear. J. Comp. Neurol. 525, 2443-2455. doi: 10. $1002 /$ cne. 24218

Hummel, J., Schöneich, S., Kössl, M., Scherberich, J., Hedwig, B., Prinz, S., et al. (2016). Gating of acoustic transducer channels is shaped by biomechanical filter processes. J. Neurosci. 36, 2377-2382. doi: 10.1523/jneurosci.3948-15. 2016

Jacobs, K., Otte, B., and Lakes-Harlan, R. (1999). Tympanal receptor cells of Schistocerca gregaria: correlation of soma positions and dendrite attachment sites, central projections and physiologies. J. Exp. Zool. 283, 270-285. doi: 10.1002/(sici)1097-010x(19990215)283:3<270::aid-jez5>3.0.co;2-c

Janvier, P. (2008). Early jawless vertebrates and cyclostome originals. Zool. Sci. 25, 1045-1056. doi: 10.2108/zsj.25.1045

Jékely, G., and Arendt, D. (2006). Evolution of intraflagellar transport from coated vesicles and autogenous origin of the eukaryotic cilium. Bioessays 28, 191-198. doi: 10.1002/bies.20369

Jin, P., Bulkley, D., Guo, Y., Zhang, W., Guo, Z., Huynh, W., et al. (2017). Electron cryo-microscopy structure of the mechanotransduction channel NOMPC. Nature 547, 118-122. doi: 10.1038/nature22981

Jin, P., Jan, L. Y., and Jan, Y. N. (2020). Mechanosensitive ion channels: structural features relevant to mechanotransduction mechanisms. Annu. Rev. Neurosci. 43, 207-229. doi: 10.1146/annurev-neuro-070918-050509

Jost, M. C., and Shaw, K. L. (2006). Phylogeny of Ensifer (Hexapoda: Orthoptera) using three ribosomal loci, with implications for the evolution of acoustic information. Mol. Phylogenet. Evol. 38, 510-530. doi: 10.1016/j.ympev.2005.10. 004
Kamikouchi, A., Inagaki, H. K., Effertz, T., Hendrich, O., Fiala, A., Göpfert, M. C., et al. (2009). The neural basis of Drosophila gravity-sensing and hearing. Nature 458, 165-171. doi: 10.1038/nature07810

Karak, S., Jacobs, J. S., Kittelmann, M., Spalthoff, C., Katana, R., Sivan-Loukianova, E., et al. (2015). Diverse roles of axonemal dyneins in Drosophila auditory neuron function and mechanical amplification in hearing. Sci. Rep. 5:17085. doi: $10.1038 /$ srep 17085

Kavlie, R. G., and Albert, J. T. (2013). Chordotonal organs. Curr. Biol. 23, R334R335. doi: 10.1016/j.cub.2013.03.048

Kavlie, R. G., Fritz, J. L., Nies, F., Göpfert, M. C., Oliver, D., Albert, J. T., et al. (2015). Prestin is an anion transporter dispensable for mechanical feedback amplification in Drosophila hearing. J. Comp. Physiol. A Neuroethol. Sens. Neural. Behav. Physiol. 201, 51-60. doi: 10.1007/s00359-014-0960-9

Kawashima, Y., Géléoc, G. S., Kurima, K., Labay, V., Lelli, A., Asai, Y., et al. (2011). Mechanotransduction in mouse inner ear hair cells requires transmembrane channel-like genes. J. Clin. Invest. 121, 4796-4809. doi: 10.1172/JCI60405

Kazmierczak, P., Sakaguchi, H., Tokita, J., Wilson-Kubalek, E. M., Milligan, R. A., Müller, U., et al. (2007). Cadherin 23 and protocadherin 15 interact to form tip-link filaments in sensory hair cells. Nature 449, 78-91. doi: 10.1038/ nature06091

Keder, A., Tardieu, C., Malong, L., Filia, A., Kashkenbayeva, A., Newton, F., et al. (2020). Homeostatic maintenance and age-related functional decline in the Drosophila ear. Sci. Rep. 10:7431. doi: 10.1038/s41598-020-64498-z

Kellenberger, S., and Schild, L. (2002). Epithelial sodium channel/degenerin family of ion channels: avariety of functions for a shared structure. Physiol. Rev. 82, 735-767. doi: 10.1152/physrev.00007.2002

Kennedy, H. J., Evans, M. G., Crawford, A. C., and Fettiplace, R. (2003). Fast adaptation of mechanoelectircal transducer channels in mammalian cochlear hear cells. Nat. Neurosci. 6, 832-836. doi: 10.1038/nn1089

Kernan, M., Cowan, D., and Zuker, C. (1994). Genetic dissection of mechanosensory transduction: mechanoreception-defective mutations of Drosophila. Neuron 12, 1195-1206. doi: 10.1016/0896-6273(94)90437-5

Killick, R., and Richardson, G. (1997). Isolation of chicken alpha ENaC splice variants from a cochlear cDNA library. Biochim. Biophys. Acta 1350, 33-37. doi: 10.1016/s0167-4781(96)00197-2

Kim, J., Chung, Y. D., Park, D. Y., Choi, S., Shin, D. W., Soh, H., et al. (2003). A TRPV family ion channel required for hearing in Drosophila. Nature 424, 81-84. doi: $10.1038 /$ nature 01733

Knoll, A. H. (2004). Life on a Young Planet - The First Three Billion Years of Evolution on Earth. Princeton, NJ: Princeton University Press.

Köppl, C., Gleich, O., and Manley, G. A. (1993). An auditory fovea in the barn owl cochlea. J. Comp. Physiol. A 171, 695-704. doi: 10.1007/bf00213066

Kössl, M. (1997). Sound emission from cochlear filters and foveae - does the auditory sense organ make sense? Naturwissenschaften 84 , 9-16. doi: 10.1007/ s001140050339

Kühne, R. (1982). Neurophysiology of the vibration sense in locusts and bushcrickets: response characteristics of single receptor units. J. Insect. Physiol. 28, 155-163. doi: 10.1016/0022-1910(82)90123-8

Kwan, K. Y., Allchorne, A. J., Vollrath, M. A., Christensen, A. P., Zhang, D. S., Woolf, C. J., et al. (2006). TRPA1 contributes to cold, mechanical, and chemical nociception but is not essential for hair-cell transduction. Neuron 50, 277-289. doi: 10.1016/j.neuron.2006.03.042

Lautenschlager, S., Gill, P. G., Luo, Z.-X., Fagan, M. J., and Rayfield, E. J. (2018). The role of miniturization in the evolution of the mammalian jaw and middle ear. Nature 561, 533-537. doi: 10.1038/s41586-018-0521-4

Lee, J., Moon, S., Cha, Y., and Chung, Y. D. (2010). Drosophila TRPN(=NOMPC) channel localizes to the distal end of mechanosensory cilia. PLoS One 5:e11012. doi: 10.1371/journal.pone.0011012

Lehnert, B. P., Baker, A. E., Gaudry, Q., Chiang, A. S., and Wilson, R. I. (2013). Distinct roles of TRP channels in auditory transduction and amplification in Drosophila. Neuron 77, 115-128. doi: 10.1016/j.neuron.2012.11.030

Lewis, R. S., and Hudspeth, A. J. (1983). Voltage- and ion-dependent conductances in solitary vertebrate hair cells. Nature 304, 538-541. doi: 10.1038/304538a0

Li, W., Feng, Z., Sternberg, P. W., and Xu, X. Z. (2006). A C. elegans stretch receptor neuron revealed by a mechanosensitive TRP channel homologue. Nature 440, 684-687. doi: 10.1038/nature04538

Liang, X., Madrid, J., Gärtner, R., Verbavatz, J. M., Schiklenk, C., WilschBräuninger, M., et al. (2013). A NOMPC-dependent membrane- microtubule 
connector is a candidate for the gating spring in fly mechanoreceptors. Curr. Biol. 23, 755-763. doi: 10.1016/j.cub.2013.03.065

Liang, X., Madrid, J., Saleh, H. S., and Howard, J. (2010). NompC, a member of the TRP channel family, localizes to the tubular body and distal cilium of Drosophila campaniform and chordotonal receptor cells. Cytoskelton 68, 1-7. doi: $10.1002 / \mathrm{cm} .20493$

Liang, X., Madrid, J., Saleh, H. S., and Howard, J. (2011). NOMPC, a member of the TRP channel family, localizes to the tubular body and distal cilium of Drosophila campaniform and chordotonal receptor cells. Cytoskeleton 68, 1-7.

Liberman, M. C., Gao, J., He, D. Z. Z., Wu, X., Jia, S., and Zuo, J. (2002). Prestin is required for electromotility of the outer hair cell and for the cochlear amplifier. Nature 419, 300-304. doi: 10.1038/nature01059

Liu, Y., Chi, H., Li, L., Rossiter, S. J., and Zhang, S. (2018). Molecular data support an early shift to an intermediate-light niche in the evolution of mammals. Mol. Biol. Evol. 35, 1130-1134. doi: 10.1093/molbev/msy019

Lombard, R. E., and Bolt, J. R. (1979). Evolution of the tetrapod ear: an analysis and reinterpretation. Biol. J. Linn. Soc. 11, 19-76. doi: 10.1111/j.1095-8312.1979. tb00027.x

Lopatin, A. V. (2019). Modern data on the origin and early radiation of mammals. Biol. Bull. 46, 744-750. doi: 10.1134/s1062359019070082

Luo, Z.-X., and Ketten, D. R. (1991). CT scanning and computerized reconstructions of the inner ear of multituberculate mammals. J. Vertebr. Paleontol. 11, 220-228. doi: 10.1080/02724634.1991.10011389

MacNaughton, R. B., Zonneveld, J.-P., and Utting, J. (2002). Outcrop Analysis Of Trace Fossil Assemblages in the Toad Formation (Triassic), SE Yukon Territory: Implications For Hydrocarbon Exploration in NE British Columbia. Calgary, AB: Canadian Society of Petroleum Geologists Abstracts with Programs, 216.

Madrid, R., and Bacigalupo, J. (2015). TRP Channels in Sensory Transduction. Berlin: Springer.

Maeda, R., Kindt, K. S., Mo, W., Morgan, C. P., Erickson, T., Zhao, H., et al. (2014). Tip-link protein protocadhein 15 interacts with transmembrane channel-like proteins TMC1 and TMC2. Proc. Natl. Acad. Sci. U.S.A. 111, 12907-12912. doi: 10.1073/pnas.1402152111

Malkin, R., McDonagh, T. R., Mhatre, N., Scott, T. S., and Robert, D. (2013). Energy localization and frequency analysis in the locust ear. J. R. Soc. Interface 11:20130857. doi: 10.1098/rsif.2013.0857

Mallatt, J. (1996). Ventilation and the origin of jawed vertebrates: a new mouth. Zool. J. Linn. Soc. 117, 329-404. doi: 10.1111/j.1096-3642.1996.tb01658.x

Manley, G. A. (2000). Cochlear mechanisms from a phylogenetic viewpoint. Proc. Natl. Acad. Sci. U.S.A. 97, 11736-11743. doi: 10.1073/pnas.97.22.11 736

Marcotti, W., Corns, L. F., Desmonds, T., Kirkwood, N. K., Richardson, G. P., and Kros, C. J. (2014). Transduction without tip links in cochlear hair cells is mediated by ion channels with permeation properties distinct from those of the mechano-electrical transducer channel. J. Neurosci. 34, 5505-5514. doi: 10.1523/JNEUROSCI.4086-13.2014

Martin, P., and Hudspeth, A. J. (1999). Active hair-bundle movements can amplify a hair cell's response to oscillatory mechanical stimuli. Proc. Natl. Acad. Sci. U.S.A. 96, 14306-14311. doi: 10.1073/pnas.96.25.14306

Martin, P., Mehta, D., and Hudspeth, A. J. (2000). Negative hair-bundle stiffness betrays a mechanism for mechanical amplification by the hair cell. Proc. Natl. Acad. Sci. U.S.A. 97, 12026-12031. doi: 10.1073/pnas.210389 497

Meng, J., and Wyss, A. R. (1995). Monotreme affinities and low frequency hearing suggested by multituberculate ear. Nature 377, 141-144. doi: 10.1038/377141a0

Mhatre, N. (2015). Active amplification in insect ears: mechanics models and molecules. J. Comp. Physiol. A 201, 19-37. doi: 10.1007/s00359-0140969-0

Mhatre, N., and Robert, D. (2013). A tympanal insect ear exploits a critical oscillator for active amplification and tuning. Curr. Biol. 23, 1952-1957. doi: 10.1016/j.cub.2013.08.028

Michaely, P., Tomchick, D. R., Machius, M., and Anderson, R. G. (2002). Crystal structure of a 12 ANK repeat stack from human ankyrinR. EMBO J. 21, 6387-6396. doi: 10.1093/emboj/cdf651

Michelsen, A. (1971). The physiology of the locust ear. I. Frequency sensitivity of single cells in the isolated ear. II. Frequency discrimination based upon resonances in the tympanum. III. Acoustical properties of the intact ear. Z. Vergl. Physiol. 71, 49-128. doi: 10.1007/978-3-662-40271-9_1
Michelsen, A., Popov, A. V., and Lewis, B. (1994). Physics of directional hearing in the cricket Gryllus bimaculatus. J. Comp. Physiol. A 175, 153-164. doi: 10.1007/bf00215111

Misof, B., Liu, S., Meusemann, K., Peters, R. S., Donath, A., Mayer, C., et al. (2014). Phylogenomics resolves the timing and patter of insect evolution. Science 346, 763-767. doi: 10.1126/science. 1257570

Mitchell, D. R. (2004). Speculations on the evolution of $9+2$ orgamelles and the role of central pair microtubules. Biol. Cell 96, 691-696. doi: 10.1016/j.biolcel.2004. 07.004

Mitchell, D. R. (2007). The evolution of eukaryotic cilia and flagella as motile nad sensory organelles. Adv. Exp. Med. Biol. 607, 130-140. doi: 10.1007/978-0-38774021-8_11

Möckel, D., Kössl, M., Lang, J., and Nowotny, M. (2012). Temperature dependence of distortion-product otoacoustic emissions in tympanal organs of locusts. J. Exp. Biol. 215, 3309-3316. doi: 10.1242/jeb.074377

Montealegre-Z, F., and Robert, D. (2015). Biomechanics of hearing in katydids. J. Comp. Physiol. A 201, 5-18. doi: 10.1007/s00359-014-0976-1

Montealegre-Z, F., Jonsson, T., Robson-Brown, K. A., Postles, M., and Robert, D. (2012). Convergent evolution between insect and mammalian audition. Science 338, 968-971. doi: 10.1126/science.1225271

Moran, J., McKean, P. G., and Ginger, M. L. (2014). Aukaryotic flagella: variations in form, function, and composition during evolution. Bioscience 64, 1103-1114. doi: 10.1093/biosci/biu175

Müller, M., Laube, B., Burda, H., and Bruns, V. (1992). Structure and function of the cochlea in the African mole rat (Cryptomys hottentotus): evidence for a low frequency acoustic fovea. J. Comp. Physiol. A 171, 469-476. doi: 10.1111/j.14697998.1990.tb04319.x

Nadrowski, B., Albert, J. T., and Göpfert, M. C. (2008). Transducer-based force generation explains active process in Drosophila hearing. Curr. Biol. 18, 13651372. doi: 10.1016/j.cub.2008.07.095

Neuweiler, G., and Schmidt, S. (1993). Audition in echolocating bats. Curr. Opin. Neurobiol. 3, 563-569. doi: 10.1016/0959-4388(93)90057-6

Nin, F., Reichenbach, T., Fisher, J. A., and Hudspeth, A. J. (2012). Contribution of active hair- bundle motility to nonlinear amplification in the mammalian cochlea. Proc. Natl. Acad. Sci. U.S.A. 109, 21076-21080. doi: 10.1073/pnas. 1219379110

Nonaka, S., Tanaka, Y., Okada, Y., Takeda, S., Harada, A., Kanai, Y., et al. (1998). Randomization of left-right asymmetry due to loss of nodal cilia generating leftward flow of extraembryonic fluid in mice lacking KIF3B motor protein. Cell 95, 829-837. doi: 10.1016/s0092-8674(00)81705-5

Nowotny, M., Hummel, J., Weber, M., Möckel, D., and Kössl, M. (2010). Acousticinduced motion of the bushcricket (Mecopoda elongata, Tettigoniidae) tympanum. J. Comp. Physiol. A 196, 939-945. doi: 10.1007/s00359-010-0577-6

Ó Maoiléidigh, D., and Ricci, A. J. A. (2019). Bundle of mechanisms: inner-ear hair-cell mechanotransduction. Trends Neurosci. 42, 221-236. doi: 10.1016/j. tins.2018.12.006

O'Hagan, R., Chalfie, M., and Goodman, M. B. (2005). The MEC-4 DEG/ENaC channel of Caenorhabditis elegans touch receptor neurons transduces mechanical signals. Nat. Neurosci. 8, 43-50. doi: 10.1038/nn1362

Olson, E. S., and Nowotny, M. (2019). Experimental and theoretical explorations of traveling waves and tuning in the bushcricket ear. Biophys. J. 116, 165-177. doi: 10.1016/j.bpj.2018.11.3124

Pan, B., Akyuz, N., Liu, X. P., Asai, Y., Nist-Lund, C., Kurima, K., et al. (2018). TMC1 forms the pore of mechanosensory transduction channels in vertebrate inner ear hair cells. Neuron 99, 736.e-753.e. doi: 10.1016/j.neuron.2018.07.033

Pan, B., Géléoc, G. S., Asai, Y., Horwitz, G. C., Kurima, K., Ishikawa, K., et al. (2013). TMC1 and TMC2 are components of the mechanotransduction channel in hair cells of the mammalian inner ear. Neuron 79, 504-515. doi: 10.1016/j. neuron.2013.06.019

Peng, A. W., and Ricci, A. J. (2011). Somatic motility and hair bundle mechanics, re both necessary for cochlear amplification? Hear. Res. 273, 109-122. doi: 10.1016/j.heares.2010.03.094

Peng, A. W., Effertz, T., and Ricci, A. J. (2013). Adaptation of mammalian auditory hair cell mechanotransduction is independent of calcium entry. Neuron 20, 960-972. doi: 10.1016/j.neuron.2013.08.025

Peterson, K. J., and Butterfield, N. J. (2005). Origin of the Eumetazoa: testing ecological predictions of molecular clocks against the fossil record. Proc. Natl. Acad. Sci. U.S.A. 102, 9547-9552. doi: 10.1073/pnas.0503660102 
Peterson, K. J., Lyons, J. B., Nowak, K. S., Takacs, C. M., Wargo, M. J., and McPeek, M. A. (2004). Estimating metazoan divergence times in a molecular clock. Proc. Natl. Acad. Sci. U.S.A. 101, 6536-6541. doi: 10.1073/pnas.0401670101

Plotnick, R. E., and Smith, D. M. (2012). Exceptionally preserved fossil insect ears from the Eocene Grenn river formation of Colorado. J. Paleontol. 86, 19-24. doi: 10.1666/11-072.1

Popper, N., and Fay, R. (1997). Evolution of the ear and hearing: issues and questions. Brain Behav. Evol. 50, 213-221. doi: 10.1159/000113335

Qiu, X., and Müller, U. (2018). Mechanically gated ion channels in mammalian hair cells. Front. Cell Neurosci. 12:100. doi: 10.3389/fncel.2018.00100

Ramirez, M. D., Pairett, A. N., Pankey, M. S., Serb, J. M., Speiser, D. I., Swafford, A. J., et al. (2016). The last common ancestor of most bilaterian animals possessed at least nine opsins. Genome Biol. Evol. 1, 3640-3652.

Reichert, C. (1837). Über die visceralbogen der wirbeltiere im allgemeinen und deren metamorphosen bei den vögeln und säugetieren. Arch. Anat. Physiol. Wissensch. Med. 1837, 120-222.

Robert, D., Miles, R. N., and Hoy, R. R. (1996). Directional hearing by mechanical coupling in the parasitoid fly Ormia ochracea. J. Comp. Physiol. A 179, 29-44. doi: 10.1007/BF00193432

Robles, L., and Ruggero, M. A. (2001). Mechanics of the mammalian cochlea. Physiol. Rev. 81, 1305-1352. doi: 10.1152/physrev.2001.81.3.1305

Römer, H. (1976). Die informationsverarbeitung tympanaler rezeptorelemente von Locusta migratoria (Acrididae, Orthoptera). [Pro-cessing of information by tympanal receptors of Locusta migratoria (Acrididae, Orthoptera)]. J. Comp. Physiol. A 109, 101-122. doi: 10.1007/bf00663438

Russell, I. J., and Sellick, P. M. (1978). Intracellular studies of hair cells in the mammalian cochlea. J. Physiol. 284, 261-290. doi: 10.1113/jphysiol.1978. sp012540

Rust, J., Stumpner, A., and Gottwald, J. (1999). Singing and hearing in Tertiary bushcrickets. Nature 399:650. doi: 10.1038/21356

Saier, M. H. Jr. (2016). Transport protein evolution deduced from analysis of sequence, topology and structure. Curr. Opin. Struct. Biol. 38, 9-17. doi: 10. 1016/j.sbi.2016.05.001

Satir, P., Mitchell, D. R., and Jékely, G. (2008). "How did the cilium evolve?" in Ciliary Function in Mammalian Development, ed. B. K. Yoder (Cambridge, MA: Academic Press).

Scherberich, J., Hummel, J., Schöneich, S., and Nowotny, M. (2016). Auditory fovea in the ear of a duetting katydid shows male-specific adaptation to the female call. Curr. Biol. 26, R1222-R1223.

Scherberich, J., Hummel, J., Schöneich, S., and Nowotny, M. (2017). Functional basis of the sexual dimorphism in the auditory fovea of the duetting bushcricket Ancylecha fenestrata. Proc. Biol. Sci. 284:20171426. doi: 10.1098/rspb.2017.1426

Schnupp, J. W., and Carr, C. E. (2009). On hearing with more than one ear: lessons from evolution. Nat. Neurosci. 12, 692-697. doi: 10.1038/nn.2325

Shaw, S. R. (1994). Detection of airborne sound by a cockroach 'vibration detector': a possible missing link in insect auditory evolution. J. Exp. Biol. 193, 13-47. doi: 10.1242/jeb.193.1.13

Shin, J. B., Adams, D., Paukert, M., Siba, M., Sidi, S., Levin, M., et al. (2005). Xenopus TRPN1 (NOMPC) localizes to microtubule-based cilia in epithelial cells, including inner-ear hair cells. Proc. Natl. Acad. Sci. U.S.A. 102, $12572-$ 12577. doi: 10.1073/pnas.0502403102

Shingyoji, C., Higuchi, H., Yoshimura, M., Katayama, E., and Yanagida, T. (1998). Dynein arms are oscillating force generators. Nature 393, 711-714. doi: 10.1038/ 31520

Sidi, S., Friedrich, R. W., and Nicolson, T. (2003). NompC TRP channel required for vertebrate sensory hair cell mechanotransduction. Science 301, 96-99. doi: $10.1126 /$ science. 1084370

Stauffer, E. A., Scarborough, J. D., Hirono, M., Miller, E. D., Shah, K., Mercer, J. A., et al. (2005). Fast adaptation in vestibular hair cells requires myosin-1c activity. Neuron 18, 541-553. doi: 10.1016/j.neuron.2005.07.024

Stensiö, E. A. (1927). The Downtonian and Devonian Vertebrates of Spitsbergen. Part I. Family Cephalaspidae. Skrifter, Vol. 12. Oslo: I kommisjon hos Jacob Dybwad, 391.

Strauß, J., and Lakes-Harlan, R. (2008). Neuroanatomy and physiology of the complex tibial organ of an atympanate ensiferan, Ametrus tibialis (Brunner von Wattenwyl, 1888) (Gryllacrididae, Orthoptera) and evolutionary implications. Brain Behav. Evol. 71, 167-180. doi: 10.1159/000114405
Strauß, J., and Lakes-Harlan, R. (2014). "Evolutionary and phylogenetic origins of tympanal hearing organs in insects," in Insect Haring Organs in Insects, ed. B. Hedwig (Berlin: Springer). doi: 10.1007/978-3-642-40462-7_2

Su, M. P., Andrés, M., Boyd-Gibbins, N., Somers, J., and Albert, J. T. (2018). Sex and species specific hearing mechanisms in mosquito flagellar ears. Nat. Commun. 9:3911.

Sueur, J., Windmill, J. F., and Robert, D. (2006). Tuning the drum: the mechanical basis for frequency discrimination in a Mediterranean cicada. J. Exp. Biol. 209, 4115-4128. doi: 10.1242/jeb.02460

Thurm, U., and Küppers, J. (1980). "Epithelial physiology of insect sensilla," in Insect Biology of the Future, eds M. Löcke and D. S. Smith (New York: Academic), 735-763. doi: 10.1016/b978-0-12-454340-9.50039-2

Thurm, U., Erler, G., Godde, J., Kastrup, H., Keil, T., Volker, W., et al. (1983). Cilia specialized for mechanoreception. J. Submicrosc. Cytol. Pathol. 15, 151-155.

Todi, S. V., Sharma, Y., and Eberl, D. F. (2004). Anatomical and molecular design of the Drosophila antenna as a flagellar auditory organ. Microsc. Res. Tech. 63, 388-399. doi: 10.1002/jemt.20053

Udayashankar, A. P., Kössl, M., and Nowotny, M. (2012). Tonotopically arranged traveling waves in the miniature hearing organ of bushcrickets. PLoS One 7:e31008. doi: 10.1371/journal.pone.0031008

Udayashankar, A. P., Kössl, M., and Nowotny, M. (2014). Lateralization of travelling wave response in the hearing organ of bushcrickets. PLoS One 9:e86090. doi: 10.1371/journal.pone.0086090

van Bergeijk, W. A. (1967). The evolution of vertebrate hearing. Contrib. Sens. Physiol. 2, 1-49. doi: 10.1016/b978-1-4831-6749-7.500007-6

von Békésy, G. (1952). DC resting potentials inside the cochlear partition. J. Acoust. Soc. Am. 24:72. doi: 10.1121/1.1906851

von Békésy, G. (1960). Experiments in Hearing. New York, NY: McGraw-Hill.

Walker, R. G., Willingham, A. T., and Zuker, C. S. (2000). A Drosophila mechanosensory transduction channel. Science 287, 2229-2234. doi: 10.1126/ science.287.5461.2229

Wang, V. Y., Hassan, B. B., Bellen, H. J., and Zoghbi, H. Y. (2002). Drosophila atonal fully resuces the phenotype of Math1 null mice: new functions evolve in new cellular contexts. Curr. Biol. 17, 1611-1616. doi: 10.1016/s0960-9822(02) 01144-2

Warren, B., and Matheson, T. (2018). The role of the mechanotransduction ion channel candidate nanchung-inactive in auditory transduction in an insect ear. J. Neurosci. 38, 3741-3752. doi: 10.1523/JNEUROSCI.2310-17.2018

Warren, B., Lukashkin, A. N., and Russell, I. J. (2010). The dynein-tubulin motor powers active oscillations and amplification in the hearing organ of the mosquito. Proc. Biol. Sci. 277, 1761-1769. doi: 10.1098/rspb.2009.2355

Weber, T., Göpfert, M. C., Winter, H., Zimmermann, U., Kohler, H., Meier, A., et al. (2003). Expression of prestin-homologous solute carrier (SLC26) in auditory organs of nonmammalian vertebrates and insects. Proc. Natl. Acad. Sci. U.S.A. 100, 7690-7695. doi: 10.1073/pnas.1330557100

Weinberger, S., Topping, M. P., Yan, J., Claeys, A., Geest, N., Ozbay, D., et al. (2017). Evolutionary changes in transcription factor coding sequence quantitatively alter sensory organ development and function. Elife 6:e26402. doi: 10.7554/ eLife. 26402

West, C. D. (1985). The relationship of the spiral turns of the cochlea and the length of the basilar membrane to the range of audible frequencies in ground dwelling mammals. J. Acoust. Soc. Am. 77, 1091-1101. doi: 10.1121/1.392227

Wever, E. G. (1978). The function of the middle in Lizard: divergent type. J. Exp. Zool. 184, 97-126.

Windmill, J. F. C., Göpfert, M. C., and Robert, D. (2005). Tympanal travelling waves in migratory locusts. J. Exp. Biol. 208, 157-168. doi: 10.1242/jeb.01332

Wu, J., Lewis, A. H., and Grandl, J. (2017). Touch, tension, and transduction - the function and regulation of piezo ion channels. Trends Biochem. Sci. 42, 57-71. doi: 10.1016/j.tibs.2016.09.004

Xu, P.-X., Zhang, X., Heaney, S., Yoon, A., Michelson, A. M., and Mass, R. L. (1999). Regulation of Pax6 expression is converved between mice and flies. Development 126, 383-395. doi: 10.1242/dev.126.2.383

Yack, J. E. (2004). The structure and function of auditory chordotonal organs in insects. Microsc. Res. Tech. 63, 315-337. doi: 10.1002/jemt.20051

Yack, J. E., and Fullard, J. H. (1990). The mechanoreceptive origin of insect tympanal organs: a comparative study of similar nerves in tympanate and atympanate moths. J. Comp. Neurol. 300, 523-534. doi: 10.1002/cne.903000407 
Yack, J. E., and Fullard, J. H. (1993). What is an insect ear? Ann. Entomol. Soc. Am. 86, 677-682. doi: 10.1093/aesa/86.6.677

Yan, Z., Zhang, W., He, Y., Gorczyca, D., Xiang, Y., Cheng, L. E., et al. (2013). Drosophila NOMPC is a mechanotransduction channel subunit for gentle-touch sensation. Nature 493, 221-225. doi: 10.1038/nature11 685

Zenner, H. P. (1986). Motile responses in outer hair cells. Hear. Res. 22, 83-90. doi: 10.1016/0378-5955(86)90082-1

Zeuner, F. E. (1939). Fossil Orthoptera Ensifera. London: British Museum Natural History.

Zhang, W., Cheng, L. E., Kittelmann, M., Li, J., Petkovic, M., Cheng, T., et al. (2015). Ankyrin repeats convey force to gate the NOMPC mechanotransduction channel. Cell 162, 1391-1403. doi: 10.1016/j.cell.2015.08. 024

Zheng, J., Shen, W. X., He, D. Z., Kevin, B. L., Madison, L. D., and Dallos, P. (2000). Prestin is the motor protein of cochlear outer hair cells. Nature 405, 149-155. doi: $10.1038 / 35012009$

Zhexi, L., Crompton, A. W., and Lucas, S. G. (1995). Evolutionary origins of the mammalian Promontorium and cochlea. J. Vertebr. Paleontol. 15, 113-121. doi: 10.1080/02724634.1995.10011211
Zhu, M., Yu, X., Ahlberg, P. E., Choo, B., Lu, J., Qiao, T., et al. (2013). A silurian placoderm with osteichthyan-like marginal jaw bones. Nature 502, 188-193. doi: $10.1038 /$ nature 12617

Conflict of Interest: The authors declare that the research was conducted in the absence of any commercial or financial relationships that could be construed as a potential conflict of interest.

Publisher's Note: All claims expressed in this article are solely those of the authors and do not necessarily represent those of their affiliated organizations, or those of the publisher, the editors and the reviewers. Any product that may be evaluated in this article, or claim that may be made by its manufacturer, is not guaranteed or endorsed by the publisher.

Copyright $\odot 2021$ Warren and Nowotny. This is an open-access article distributed under the terms of the Creative Commons Attribution License (CC BY). The use, distribution or reproduction in other forums is permitted, provided the original author(s) and the copyright owner(s) are credited and that the original publication in this journal is cited, in accordance with accepted academic practice. No use, distribution or reproduction is permitted which does not comply with these terms. 